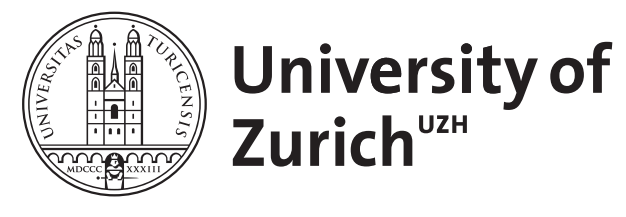

\title{
Fairness, errors and the power of competition
}

\author{
Fischbacher, Urs ; Fong, C M ; Fehr, Ernst
}

\begin{abstract}
In this paper, we investigate the effects of competition on bargained outcomes. We show that the neglect of either fairness concerns or decision errors will prevent a satisfactory understanding of how competition affects bargaining. We conducted experiments which demonstrate that introducing a small amount of competition to a bilateral ultimatum game - by adding just one competitor - induces large behavioral changes among responders and proposers, causing large changes in accepted offers. Models that assume that all people are self-interested and fully rational do not adequately explain these changes. We show that a model which combines heterogeneous fairness concerns with decision errors correctly predicts the comparative static effects of changes in competition. Moreover, the combined model is remarkably good at predicting the entire distribution of offers in many different competitive situations.
\end{abstract}

DOI: https://doi.org/10.1016/j.jebo.2009.05.021

Posted at the Zurich Open Repository and Archive, University of Zurich

ZORA URL: https://doi.org/10.5167/uzh-43698

Journal Article

Accepted Version

Originally published at:

Fischbacher, Urs; Fong, C M; Fehr, Ernst (2009). Fairness, errors and the power of competition. Journal of Economic Behavior Organization, 72(1):527-545.

DOI: https://doi.org/10.1016/j.jebo.2009.05.021 


\title{
Fairness, Errors and the Power of Competition $^{1}$
}

\author{
Urs Fischbacher, ${ }^{*}$ Christina M. Fong, ${ }^{* *}$ and Ernst Fehr***+ \\ December 16, 2008
}

\begin{abstract}
In this paper, we investigate the effects of competition on bargained outcomes. We show that the neglect of either fairness concerns or decision errors will prevent a satisfactory understanding of how competition affects bargaining. We conducted experiments which demonstrate that introducing a small amount of competition to a bilateral ultimatum game - by adding just one competitor - induces large behavioral changes among responders and proposers, causing large changes in accepted offers. Models that assume that all people are self-interested and fully rational do not adequately explain these changes. We show that a model which combines heterogeneous fairness concerns with decision errors correctly predicts the comparative static effects of changes in competition. Moreover, the combined model is remarkably good at predicting the entire distribution of offers in many different competitive situations.

* Department of Economics

University of Konstanz

Box D-131

D- 78457 Konstanz (Germany)

Email: Urs.Fischbacher@uni-konstanz.de

*** Institute for Empirical Research in Economics

University of Zurich

Blümlisalpstrasse 10

CH-8006 Zürich

Email: efehr@iew.uzh.ch

$+\quad$ Corresponding author

**Department of Social and Decision Sciences Carnegie Mellon University

Pittsburgh, PA 15213

Email: fong2@andrew.cmu.edu
\end{abstract}

Keywords: Competition, Fairness, Reciprocity, Quantal Response Equilibrium

JEL-Classification: C91, C92, D40

\footnotetext{
${ }^{1}$ Ernst Fehr acknowledges support by the Swiss National Science Foundation (project number 105314-114107) and Research Priority Program of the University of Zurich on the "Foundations of Human Social Behavior". Christina Fong gratefully acknowledges funding from the Economic Science Laboratory at the University of Arizona, the MacArthur Foundation Network on Inequality, and the MacArthur Foundation Network on Norms and Preferences. We thank the participants of the Rational Choice Seminar at the University of Chicago and of seminars at Northwestern University and the University of Amsterdam, and two anonymous referees for helpful comments.
} 


\section{Introduction}

Economists have long been interested in how changes in competition affect bargained outcomes. In this paper, we argue that no satisfactory answer can be given to this basic question if one neglects the presence of fairness motives and decision errors. ${ }^{1}$ It is well-known that the prevailing model, which assumes that individuals are both perfectly rational and motivated exclusively by selfinterest, prevents a full understanding of how competition affects bargaining behavior. As a result, neither the level of bargained offers nor the basic comparative static properties of offers with regard to changes in competition can be fully understood. We show that a model which takes heterogeneous fairness preferences and decision errors into account explains both the offer level and the qualitative and quantitative effects of changes in competition.

Our argument is based on data from of a series of laboratory ultimatum and market game experiments in combination with predictions from recently developed fairness models and quantal response models which capture the impact of decision errors on equilibrium behavior. ${ }^{2}$ Our data indicate that both fairness preferences and decision errors are crucial for understanding competition. We show, in particular, that the combination of the fairness and the quantal response equilibrium approaches not only captures the comparative static aspects of proposer and responder behavior quite well but also makes precise quantitative predictions of average offers and the whole distribution of offers across all of our experiments. Thus, our paper addresses the question of when and how deviations from full rationality and self-interest should be taken into account. Becker (1962) showed that these deviations from the traditional model may sometimes be of second order importance. However, as our results show, it would be a serious mistake to assume that this is always the case.

The starting point of our investigation is a bilateral ultimatum game in which a responder and a proposer bargain over a sum of money. The proposer can make exactly one offer to the responder,

\footnotetext{
${ }^{1}$ There is now a large body of evidence indicating that a non-negligible number of people care not only about their own material payoff but also about fairness. It has been shown that fairness motives are behaviorally important even under rather high stake levels and in a wide variety of contexts. For surveys about the role of fairness concerns in strategic interactions, see Camerer (2003) or Fehr and Schmidt (2003). In addition, there is a lot of evidence indicating that many individuals deviate from perfect rationality (Camerer 2003).

${ }^{2}$ Recently developed fairness models include Rabin (1993), Levine (1998), Fehr and Schmidt (1999), Dufwenberg and Kirchsteiger (1999), Falk and Fischbacher (2006) and Bolton and Ockenfels (2000). The quantal response equilibrium approach, which captures the idea of noisy best reply behavior, was developed by McKelvey and Palfrey (1995). Goeree and Holt (2000, 2001), Goeree, Holt and Palfrey (2002) and Goeree, Holt and Laury (2002) successfully applied the approach to explain the salient behavioral features of many different games. For a critical discussion of the quantal response approach see Haile, Hortacsu and Kosenok (2008).
} 
which the latter can accept or reject. If the offer is rejected, both players earn zero. If the offer is accepted, each player earns the amount that was proposed by the proposer. Then, we analyze market experiments in which we add competing responders or proposers to the bilateral game in order to examine the impact of competition on bargaining. The prevailing model predicts that the proposer should reap virtually the whole surplus in the bilateral bargaining game. However, it is well known that this is generally not the case because the responders resist unfair offers (Güth, Schmittberger and Schwarze 1982, Güth and Tietz 1990, Roth 1995). The question then is how a little bit of competition - the addition of just one competing responder or proposer - affects accepted offers, and, if so, what the underlying mechanisms are.

We find that the addition of just one competitor has a very large impact on accepted offers. The introduction of competition between two responders reduces their average share of the gains from trade from 42 percent to roughly 20 percent. Moreover, if we increase the competition to a total of five competing responders, their average share falls further to $12-14$ percent. Thus, competition among responders has a strong and unambiguous impact on accepted offers, and there is a sharp discontinuity between no competition and a little bit of competition. The introduction of competition between two proposers further supports this discontinuity. In this case, the responder's average share of the pie increases from 42 percent to roughly 75 percent.

Intuitively, self-interest seems to be an important driving force behind the effects of competition. It is, therefore, ironic that the prevailing model is unable to capture the powerful effects of responder competition. According to this model, the proposers already reap the entire pie in the bilateral situation. Thus, the introduction of responder competition can have no impact on accepted offers. In contrast, an approach which assumes heterogeneous fairness preferences can explain both why the proposer makes greedier offers and why the responders are willing to accept the proposer's lower offers. It predicts, in particular, that fairness seeking responders are less likely to reject low offers if they believe that the competing responder(s) will accept these offers. The data fully supports this prediction. ${ }^{3}$ In fact, the responders' expectations about their rivals' acceptance

\footnotetext{
${ }^{3}$ Our responder and proposer competition treatments are markets with complete contracts. When the labor contract is incomplete, as it is in the gift-exchange game, fairness models predict and experiments show that competition has little effect on wages. The reason, according to fairness models, is that despite the presence of worker (responder) competition, workers can enforce a fair outcome after they accept an offer. This motivates firms (proposers) to offer higher wages even in the presence of worker competition. Because wages are high even with worker competition, removing worker competition or even introducing firm competition should not affect the wage as much as it would if contracts were complete (Fehr and Schmidt 1999). Empirical results support this prediction (Fehr, Kirchsteiger and Riedl 1993, Fehr and Falk 1999, Brandts and Charness 2004).
} 
behavior is the major determinant of changes in responder behavior across different competitive situations. $^{4}$

In proposer competition, the fairness approach correctly predicts the qualitative comparative static effect of introducing competition but overestimates the effect quantitatively. Like the prevailing model, the fairness approach predicts that the proposers gain virtually nothing from trade when at least two proposers compete with each other. However, we find that the trading proposer still receives a non-negligible share. The combination of the fairness approach with the quantal response equilibrium (QRE) approach solves this problem. If there is competition among proposers, decision errors are of first order importance because they weaken the proposers' incentives to overbid each other decisively. In the absence of decision errors, Bertrand-like competition will force the proposers to outbid each other until the entire pie goes to the responder. However, in an equilibrium based on fairness preferences and decision errors, proposer $i$ knows that competing proposer $j$ is likely to make an offer where he retains a sizeable share of the pie. Hence, $i$ has no incentive to offer the whole pie to the responder.

In addition, the combination of the fairness and QRE approaches correctly captures the other major qualitative results of our experiments. First, in the bilateral case, a considerable willingness to reject unfair offers severely constrains the proposer's offer decision. Second, as the number of competing responders increases, their willingness to reject a given offer decreases substantially. Third, this reduction in the willingness to reject is due to the impact of competition on responders' beliefs about their rivals' rejection behavior. The higher the number of competing responders, the greater is a given responder's probability belief that one of the other responders will accept the offer. Fourth, an increase in the number of competing responders causes a large decrease in the rejection risk the proposers face due to the heterogeneity in fairness preferences and the changes in responder behavior. Ultimately, the proposers take advantage of the lower rejection risk by offering the responders much less.

Finally, we show that if we apply a fully parameterized version of the combined fairness and QRE model, we can even make quantitatively accurate predictions. We use exactly the same distribution of fairness preferences assumed by Fehr and Schmidt (1999). Thus, we completely tie our hands with regard to our assumptions about fairness preferences. Nevertheless, the predicted

\footnotetext{
${ }^{4}$ Note that a selfish responder accepts any positive offer regardless of what competing responders do. Thus, the behavior of a selfish responder is not affected by the expectation about the other responders' behavior.
} 
average, median, and modal accepted offers for all four treatments are quite close to the respective actual average, median, and modal accepted offers.

There are a few other experimental papers which examine the comparative static impact of changes in competition on offers. In a pioneering study Roth, Prasnikar, Okuno-Fujiwara, and Zamir (1991) compare the results of ultimatum games with those from market games with nine competing proposers and only one responder who is forced to take the highest offer. Thus, Roth et al. (1991) introduce a very large amount of competition on the proposers' side with nine competing proposers and responder's obligation to take the highest offer in all cases. Their setting does not permit the study of the impact of a small amount of competition. The focus on proposer competition also limits the empirical insights into the comparative statics of responders' rejection behavior. Güth, Marchand, and Rulliere (1998) and Grosskopf (2003) also conducted experiments where they varied the number of competitors. Grosskopf showed, in particular, that reinforcement learning models are unable to explain important effects of competition. However, none of these papers considers the implications of fairness or QRE models and none of them provides a unified quantitative interpretation of the data in terms of fairness and decision errors. To our knowledge, Goeree and Holt (2000) is the only paper that combines the fairness approach with the QRE approach. Their paper is, however, limited to the study of bilateral bargaining behavior, i.e., they do not examine competition.

The remainder of the paper is structured as follows: Section II presents the experimental design. In Section III we discuss the predictions of the fairness approach and a QRE approach that assumes selfish preferences. This enables us to see when each of the two approaches, considered individually, fails to predict the empirical regularities. Section IV presents our experimental results. In Section V, we provide a unified interpretation of the data in terms of a combined QRE-fairness model. Section VI concludes the paper.

\section{The Experimental Design}

\section{A. Treatment Conditions}

We set up four treatment conditions to test for the effect of competition on accepted offers. In one treatment, we conducted an ultimatum bargaining game (henceforth called UG) between a responder and a proposer in which competition is completely absent. In the second treatment, we 
introduced a competing responder into the bargaining game. In the third treatment, we increased the number of competing responders from two to five. In the fourth treatment, we added a competing proposer to the ultimatum bargaining game. Henceforth, we refer to the treatment with two responders as "responder competition with two responders" (RC2), the treatment with 5 responders as "responder competition with 5 responders" (RC5) and the treatment with two proposers as "proposer competition with two proposers" (PC2).

In the $\mathrm{UG}$, a responder and a proposer have to agree on the division of a given bargaining surplus of 100 money units. The rules of the game stipulate that the proposer offers the responder an absolute share $s \in\{0,1,2,3, \ldots, 100\}$ of the surplus and the responder then either accepts or rejects this share. If the offer is accepted, the proposer's share of the surplus is $100-s$ and the responder's share is $s$. If the offer is rejected, both players earn zero.

Since we were interested in isolating the effect of one or four additional competitors, respectively, we kept the structure of the games with competition identical to that of the UG. There is just one proposer in RC2 and RC5 who makes a single offer $s \in\{0,1,2,3, \ldots, 100\}$. All responders then simultaneously accept or reject this offer. If all responders reject, all players earn zero. If at least one responder accepts, the proposer earns $100-s$ and the accepting responder earns $s$. All other responders earn zero. If several responders accept the offer, one of them is randomly chosen to receive the offer, while the others earn zero. Each accepting responder has the same probability of winning. In PC2, the two proposers simultaneously make an offer $s_{i} \in\{0,1,2,3, \ldots$, $100\}, i=1,2$. Then the responder can accept one of these offers. If the responder rejects both offers, all three players earn zero; if the offer $s_{i}(\mathrm{i}=1,2)$ is accepted, proposer $i$ earns $100-s_{i}$, proposer $j \neq$ $i$ earns zero, and the responder earns $s_{i}$.

The comparison between the ultimatum game and the treatments with two competitors either two competing responders or two competing proposers - allows us to study how the introduction of competition affects participants' behavior and accepted offers. The comparison between the treatments with two and five competing responders gives us information about how an increase in responder competition affects behavior and accepted offers. 


\section{B. Procedures}

We conducted a total of ten experimental sessions, with two sessions each in UG, RC2, and PC2 and four sessions in RC5. All sessions took place in January 1999 and January 2000. We recruited 24 subjects for each session. ${ }^{5}$ Overall 238 subjects participated in the experiments, with each subject participating in exactly one session. Subjects were students from the University of Zurich and the Swiss Federal Institute of Technology (ETH) in Zurich. The experiments were implemented with the help of the experimental software z-Tree (Fischbacher 2007).

Subjects were seated at computer terminals, where they received written instructions and entered their decisions without communicating to each other. The computer terminals were located in separate carrels so that subjects could make their decisions in complete confidentiality. Anonymity among the players was guaranteed because at no point during (or after) the experiment did subjects receive information about with whom they were interacting. The subjects earned a show-up fee of 10 Swiss francs $(\mathrm{CHF} 1 \approx \$ 0.8)$ plus earnings based on their decisions during the experiment. Their earnings averaged 23.10, 21.30 and 18.20 Swiss francs for RC5, RC2 and UG, respectively. A session lasted approximately 75 to 90 minutes. In order to maintain a constant stake size per person across the treatments, we varied the exchange rate between experimental money and Swiss Francs. The number of Swiss francs per 100 experimental money units was adjusted so that the gains from trade divided by the number of players was a constant CHF 1.20 across conditions. Thus, the value of 100 experimental money units was CHF 7.20 in RC5, CHF 3.60 in RC2, and PC2, and CHF 2.40 in the UG.

It is well known that behavior in experimental markets sometimes exhibits large changes over time. Therefore, each experimental session lasted 20 periods. Subjects were randomly matched with other players in each period. They knew nothing about the previous behavior of the subjects with whom they were matched. Random matching and the absence of reputation building opportunities ensured that subjects could not condition their current behavior on their current opponents' past behavior. The repetition of the same treatment condition over 20 periods allows us to observe whether the subjects' behavior converges to a stable pattern in the different treatments.

Subjects were randomly assigned the role of a proposer or a responder at the beginning of a session. They retained this role throughout the whole session. In each period, proposers entered an offer which was sent to the matched responders. Then the responders simultaneously decided

\footnotetext{
${ }^{5}$ Due to no-shows we had only 22 subjects in one of the UG sessions.
} 
whether to accept or reject the offer. In the RC2 treatment, responders also indicated whether they believed that the other responder would accept or reject the offer. In the RC5 treatment, responders indicated their belief about how many other responders would accept the offer. The computer screens informed subjects at the end of each period about their own actions and payoffs as well as those of their opponents. For instance, each responder was informed about the proposer's offer and payoff and the matched responder's action and payoff in RC2. Subjects received no information about the behavior and the payoff of other players outside of their group.

We used matching groups in each session. We had z-Tree randomly match subjects only with those who belonged to their matching group, and not with players in other matching groups. The advantage of this technique is that behavior in each matching group is independent of that in the other matching groups. Without matching groups, an entire session would yield only one independent observation. There were three matching groups per session in the UG, two matching groups per session in RC2 and PC2, and only one matching group per session in RC5. This resulted in 6 independent observations for the $\mathrm{UG}$, and 4 independent observations for each of the other treatments. ${ }^{6}$

\section{Predictions}

\section{A. Predictions based on Prevailing Economic Theory}

The standard prediction assuming rational and self-interested players is straightforward. In any equilibrium of the UG or the market games with responder competition, the responders will always get at most an offer of $s=1$ and the proposer's offer will always be accepted. The intuition behind these equilibrium outcomes is that selfish responders will accept any positive offer so that a selfish proposer can be sure that all responders will accept an offer of $1 .^{7}$ An important point about the prevailing model is that it does not predict a difference in the behavior of proposers and trading

\footnotetext{
${ }^{6}$ We did not tell the subjects that they were in matching groups to foster the impression that they are matched with subjects drawn from the entire group of subjects in the laboratory. This is likely to reduce the subjective probability of being rematched with a particular subject.

${ }^{7}$ There are two subgame perfect equilibria in the UG and two subgame perfect equilibrium outcomes under responder competition. The two equilibria in the UG are 1) the proposer offers one and the responder accepts all positive offers and rejects zero, and 2) the proposer offers zero and the responder accepts all offers. In responder competition, one subgame perfect equilibrium outcome is obtained if the proposer makes the minimum positive offer, i.e., $s=1$, which all responders accept. In this equilibrium, all responders have to reject $s=0$. The other equilibrium outcome is sustained by an offer of $\mathrm{s}=0$ which at least one responder accepts.
} 
responders when we move from the $\mathrm{UG}$ to responder competition. Responder competition is predicted to have no impact at all on accepted offers.

This contrasts sharply with the prediction for PC2. The addition of just one competing proposer implies that the responder receives at least 98 percent of the surplus in any subgame perfect equilibrium. There is an equilibrium in which both proposers offer $s_{i}=99$ and the responder accepts one of these offers, but there are also other equilibria. Both proposers offering 100, or both offering 98 can also be part of an equilibrium. If both offer 98 their expected payoff is 1 unit and overbidding with $s_{i}=99$ also yields 1 unit of payoff. ${ }^{8}$ However, there is always an incentive for overbidding if both proposers offer 97 or less, so that the responder receives at least 98 percent of the surplus in any equilibrium. Therefore, whereas the introduction of responder competition - no matter how strong - is predicted to have no impact on accepted offers, the introduction of proposer competition - no matter how small - implies a radical change in the accepted offer - from one that gives the responder almost nothing to one that gives the responder almost the whole surplus.

\section{B. Predictions of Fairness Models}

Several fairness models have been recently developed that capture the idea that a substantial percentage of the subjects is motivated not only by self-interest but also by concerns about equity (Fehr and Schmidt 1999, Bolton and Ockenfels 2000) and reciprocity (Rabin 1993, Levine 1998, Dufwenberg and Kirchsteiger 2004, Falk and Fischbacher 2006). These models are consistent with the fact that responders in the bargaining game frequently reject low, unfair, offers, in turn inducing proposers to make fair offers. In the following, we apply the Fehr and Schmidt (FS) model to generate predictions for our experimental treatments. The main reason for this is that the model specifies a simple, tractable, functional form for subjects' preferences that allows the computation of closed form solutions. Our choice of the FS model does not mean that the other fairness models are unable to explain our experimental results. Instead, despite differences in the details, the equity and reciprocity models offer a common intuition as to why competition induces players with fairness motives to behave more like selfish players: competition undermines the ability of fairness seeking players to enforce equitable outcomes or to punish other players for unfair behavior. For example, when responder competition prevails a fairness seeking responder may no longer be able

\footnotetext{
${ }^{8} \mathrm{We}$ assume risk neutrality here which is a reasonable assumption for the prevailing stake levels in our experiment.
} 
to ensure the punishment of selfish proposers by rejecting low offers because the competing responders may accept these offers. This in turn will induce the selfish proposers to make low offers.

A key idea behind the FS model is that there are both selfish and inequity averse individuals. The inequity averse individuals derive disutility from inequity. In the context of experimental games, inequality is often a good proxy for inequity. Therefore, FS assumed that players with inequity aversion behave according to the following utility function:

$$
u_{i}=\pi_{i}-\alpha_{i} \frac{1}{n-1} \sum_{j \neq i} \max \left\{\pi_{j}-\pi_{i}, 0\right\}-\beta_{i} \frac{1}{n-1} \sum_{j \neq i} \max \left\{\pi_{i}-\pi_{j}, 0\right\}
$$

In (1) $\pi_{i}, i=1, \ldots, n$ are the monetary payoffs of the $n$ players in the game, $\alpha_{\mathrm{i}}$ is a parameter measuring the disutility of disadvantageous inequality, and $\beta_{i}$ is a parameter that captures the disutility arising from advantageous inequality. FS also assume that $\alpha_{i} \geq \beta_{i}$ and $0 \leq \beta_{i}<1$. The restriction $\beta_{i}<1$ is plausible because it implies that subjects are unwilling to burn money in order to reduce advantageous inequality. In the following, we first outline the comparative static predictions for the UG and then for the markets with responder and proposer competition. ${ }^{9}$

In the UG, responders with a sufficiently high aversion to disadvantageous inequity $\left(\alpha_{i}\right)$ will reject low offers. For every given value of $\alpha_{i}$ there is a unique acceptance threshold $s$ ', meaning that offers below $s$ ' will be rejected whereas offers at or above $s$ ' will be accepted. Because the rejection of offers above $s=50$ is expensive, inequity averse responders will never reject such offers because $\beta_{i}<1$. Moreover, because responders are assumed to differ in their aversion to disadvantageous inequity, a proposer who does not know the responder's preferences faces a distribution of players with different $\alpha_{i}$-values. This means that the probability of rejection declines as the offer increases because more players are willing to accept the higher offer. Proposers who dislike advantageous inequity a lot, i.e., those with $\beta_{i}>0.5$, will propose egalitarian offers of $s=50$. The distribution of acceptance thresholds does not constrain them because even if they could enforce non-egalitarian offers without any risk of rejection they would not make such offers. This is because the transfer of $\$ 1$ to the responder decreases the payoff difference between the proposer and the responder by $\$ 2$, which produces a non-pecuniary gain of $2 \beta_{i}$ for the proposer. Thus, if $2 \beta_{i}$ exceeds the $\$ 1 \operatorname{cost}$ of the transfer, the proposer will increase the offer until equality is achieved. Those proposers with $\beta_{i}<$

\footnotetext{
${ }^{9}$ Readers who are interested in the full formal derivation of the predictions should consult the proofs of propositions 1 , 2, and 3 in Fehr and Schmidt (1999).
} 
0.5 will offer less than $\mathrm{s}=50$, maximizing their utility against the distribution of acceptance thresholds of the responders. Thus, every force that lowers the responders' willingness to reject low offers will induce the proposers with $\beta_{i}<0.5$ to take advantage of the responders' weakness and to make lower offers. This observation leads us directly to the analysis of the impact of responder competition on market outcomes because if responder competition reduces the probability that low offers are rejected the model can explain why competition lowers the offers relative to the bargaining game.

In the context of the FS model, there are two reasons why an increase in responder competition implies that the proposer faces a lower risk of not being able to trade, i.e., that all responders reject a given offer.

1. The first effect is a statistical effect in which the higher the number of responders, the higher the probability that at least one responder will accept a given offer even if competition has no effect on the distribution of acceptance thresholds. For instance, if 50 percent of the responders in the $\mathrm{UG}, \mathrm{RC} 2$, and RC5 games, respectively, have an acceptance threshold of 30 and the other 50 percent exhibit a threshold of 0 , the probability that an offer below $s=30$ is rejected is .5 in the $\mathrm{UG},(.5)^{2}$ in RC2 and only $(0.5)^{5}$ in RC5. The statistical effect arises from (i) the assumption that there is a distribution of acceptance thresholds, and (ii) the fact that if there are more responders, more responders must reject the offer to prevent that offer from ultimately being rejected.

2. The second effect is a belief effect in which increases in competition are likely to affect the responders' behavior because they affect responder beliefs about the probability that the competing responders will reject the offer. Whenever an inequity averse responder believes that another responder will accept the offer with certainty, she will accept the offer too. This is because she can no longer ensure equality by rejecting the offer, and given that there will be inequality no matter what she does, she prefers to have a chance of winning the offer; hence, she accepts. The more responders there are, the more likely it is that there is another responder who will accept the offer so that a rational responder's belief that at least one other responder will accept the offer increases. Therefore, increases in responder competition are likely to lower the responders' acceptance thresholds. ${ }^{10}$

\footnotetext{
${ }^{10}$ More precisely, it can be shown (FS 1999, proposition 3) that the highest offer $s^{h}$ that can be sustained in an equilibrium in the responder competition game depends on the acceptance threshold of the least inequity averse responder. If, for instance, the least inequity averse responder has an acceptance threshold of 20 percent, then it makes
} 
As in the UG, the predictions for proposer behavior under responder competition depend on the proposer's value of $\beta_{i}$. If $\beta_{i}$ is sufficiently high, the proposer voluntarily refrains from making an offer below $s=50$ even if such an offer could be enforced without any risk of rejection. If $\beta_{i}$ is not sufficiently high, the proposer maximizes her utility, subject to the distribution of acceptance thresholds. To be precise, the proposer will offer $\mathrm{s}=50$ if $\beta_{i}>(n-1) / n$, where $n$ is the number of players in the game. ${ }^{11}$ Hence the critical value of $\beta_{i}$ equals $1 / 2$ in the $\mathrm{UG}, 2 / 3$ in $\mathrm{RC} 2$ and $5 / 6$ in RC5 implying that the fraction of inequity averse proposers who are willing to make low offers increases if the number of responders increases. It is also worthwhile to point out that $\beta$ values at or above $2 / 3$ are likely to be rather infrequent. If $\beta_{i}$ equals $2 / 3$, the proposer in the $\mathrm{UG}$ is willing to propose an equal split even if half of the proposer's transfer is lost on the way to the responder. ${ }^{12}$ Although one cannot rule out that some players are that generous, it seems doubtful that many are.

Thus, the fairness approach predicts that if the number of responders increases, then responders are less willing to reject low offers, proposers face a lower overall rejection risk, and proposers are less likely to make the egalitarian offer. As a consequence, we expect accepted offers to decline if responder competition is introduced or increased. However, we can go beyond these qualitative predictions to make quantitative predictions.

To do this, we assume the same distribution of utility parameters as in Fehr and Schmidt 1999 (see Table 1). ${ }^{13}$ On the basis of these parameters we predict the offers and the rejection thresholds

little sense for the more inequity averse responders to reject offers above 20 percent because these offers will be accepted. Therefore, as the acceptance threshold of the least inequity averse responder decreases, so will the acceptance threshold of all other responders and so will also $s^{h}$. Adding additional responders from a heterogeneous population of subjects increases the likelihood that the least inequity averse responder will have a lower acceptance threshold. This means that an increase in the number of responders lowers the acceptance threshold of all inequity averse responders.

${ }^{11}$ It is straightforward to show that proposers will never offer more than $\mathrm{s}=50$ in the UG or in responder competition with any number of responders. It remains to be shown at which point proposers will offer at least $\mathrm{s}=50$. If there are $n$ players altogether, then an offer of one dollar to one of the responders reduces inequality between the proposer and the receiving responder by 2 dollars and reduces inequality between the proposer and each of the other $n-2$ responders by 1 dollar. Therefore, the average reduction in inequality between the proposer and all n-1 other players is $(2+n-2) /(n-1)=$ $n /(n-1)$ dollars. Thus, the non-pecuniary gain for the proposer from this reduction in inequality is $\beta[n /(n-1)]$. If this nonpecuniary gain exceeds 1 , i. e., if $\beta>(n-1) / n$, the proposer prefers to give away money to one of the responders. If, instead, $\beta<(n-1) / n$, the proposer is willing to bear the risk of being rejected by trading off a higher risk of rejection with the higher earnings from an accepted offer. For more detail, see Fehr and Schmidt (1999).

${ }^{12}$ To be precise, assume that the responder only receives $\$ \gamma$, where $\gamma<1$, for every dollar that the proposer transfers to the responder in the UG. Then the proposer's payoff function can be written as $U_{p}=100-s-\beta[(100-s)-\gamma s]$. Differentiating with respect to $\mathrm{s}$, and assuming that $\beta=2 / 3$, yields $-1+(2 / 3)(1+\gamma)$. This expression is non-negative for $\gamma \geq 1 / 2$. Thus, in the case where half of the money transferred to the responder is lost $(\gamma=1 / 2)$ the proposer is indifferent between keeping a dollar and transferring a dollar.

${ }^{13}$ This distribution of types was chosen by Fehr and Schmidt (1999) based on a review of the prior ultimatum game results. We use this distribution here and in our combined fairness-QRE model discussed in Section V because without such a restriction, one might be able to justify many outcomes. 
of the different types of players across the UG, RC2, and RC5. Table 1 shows that - with the exception of the purely selfish types- the acceptance thresholds of the different player types will be highest in the UG and lowest in RC5. Moreover, regardless of the players' types, the offers will be highest in the UG and lowest in RC5. ${ }^{14}$ The table also shows that competition homogenizes the behavior of different player types. In RC2, for instance, all types make the same offers while in the UG the selfish players and those with little inequity aversion make different offers. Similar homogenization effects are also predicted for the responders. Thus, the table neatly illustrates the powerful effects of competition on individual behavior that are predicted by the fairness model.

\section{Insert Table 1 about here}

In the case of proposer competition, the FS model predicts the same extreme outcome as does the prevailing model with selfish preferences if we rule out the unlikely case of $\beta_{i}>2 / 3$. The reason for this extreme prediction is threefold. First, as in the UG, the responder will accept offers above $1 / 2$ because rejecting such high offers is too expensive. Second, if $\beta_{i}<2 / 3$ the responder always prefers the higher offer. Third, every offer s' that gives the responder less than 98 percent of the surplus provides an incentive for the competing proposer to make an offer s" $>$ s', regardless of how strongly inequity averse they are. Overbidding has three advantages. First, it gives the overbidder a monetary payoff of (1-s"'). Second, it reduces the disadvantageous inequality with respect to the proposer. Third, it turns the disadvantageous inequality relative to the responder who made the offer s' into advantageous inequality. It can be shown that, due to these advantages, it is in the interest of the proposers to overbid until almost the whole surplus is reaped by the responder.

\section{Quantal Response Equilibrium (QRE) Models with Selfish Preferences}

The quantal response equilibrium (QRE) approach was developed by McKelvey and Palfrey (1995) and it has been successfully applied to many different contexts in recent years, ranging from all-pay auctions (Anderson, Goeree and Holt 1998) and private value auctions (Goeree, Holt and Palfrey 2002) to public goods (Goeree, Holt and Laury 2002), coordination games (Goeree and Holt 2001), and alternating offer bargaining games (Georee and Holt 2000). The key idea behind this approach

\footnotetext{
${ }^{14}$ The computations in Table 1 are based on the assumption that subjects know the distribution of types that is assumed in the table. For the UG this gives us a unique equilibrium prediction. For RC2 and RC5 there are multiple equilibria. In the table we have displayed the equilibrium with the highest sustainable equilibrium offers in RC2 and RC5.
} 
is that each individual plays the noisy best reply to the other players' noisy best replies. A noisy best reply means that subjects do not always play the best reply to the expected actions of the others. They play the best reply with the highest probability, but, due to decision errors, they also play the other available actions with positive probability. For example, the best reply for a selfish responder in the UG is to accept any positive offer. Yet, a selfish quantal response player occasionally commits the error of rejecting positive offers. Moreover, the probability of rejecting offers decreases as the cost of doing so increases. The cost of rejecting an offer is just the lost payoff, i.e. the value of the offer. Thus, the probability that the responder will reject the offer decreases in the offer size. This is a qualitatively similar prediction to those made by fairness models. Furthermore, selfish quantal response proposers have an incentive to make positive offers in the UG, as a best response to the chance that responders will erroneously reject low offers. Thus, the QRE and fairness approaches lead to similar qualitative predictions for outcomes in the UG. However, as we show below, the two approaches make qualitatively different predictions about how behaviors and outcomes are affected by introducing and increasing competition in the UG.

More formally, let $\operatorname{Pr}(i)$ denote the probability of taking action $i$, let $u^{e}(i)$ be the expected utility of action $\mathrm{i}$ for given beliefs about the strategies of the other players, let $\mu$ be the parameter that determines the distribution of decision errors and let $\mathrm{N}$ denote the number of available actions. Then, under the assumption that the error is extreme-value distributed (as, e.g., in Goeree, Holt and Palfrey 2002) ${ }^{15}$, the quantal (noisy) best replies are given by the conditions

$$
\operatorname{Pr}(i)=\frac{\exp \left(u^{e}(i) / \mu\right)}{\sum_{j=1}^{N} \exp \left(u^{e}(j) / \mu\right)}, \quad i=1, \ldots, N
$$

If the subjective probabilities of the actions that enter into the calculation of the expected utility of action $i$ are the same as the probabilities $\operatorname{Pr}(i)$ that are determined according to (2) by the expected utility $u^{e}(i)$, a quantal response equilibrium prevails.

Figure 1 shows the offer distribution for the UG in a QRE for three different assumptions about the error parameter $\mu$. In all three cases we assumed that the players have completely selfish preferences. Thus, the figure illustrates the ability of the QRE approach with selfish preferences to

\footnotetext{
${ }^{15}$ Assuming an extreme value distribution leads to a logistic model in which it is easy to determine the equilibrium. Using other error term distributions would complicate the analysis substantially without clear gain. The extreme value distribution is the most commonly used distribution in the quantal response literature, presumably because of its tractability (Haile, Hortaçsu and Kosenok 2008).
} 
predict positive offers in the UG. Figure 1 also indicates that it is even possible to generate predictions of average offers in the range between 30 and 40. However, such average offers can only be part of a QRE equilibrium if the error parameter is very high and a large percentage of the offers is above 50 .

The comparative static predictions of the QRE approach with selfish responders are illustrated in Figure 2. To construct Figure 2, we assumed that a constant error parameter of $\mu=4$ across the $\mathrm{UG}, \mathrm{RC} 2$, and RC5. ${ }^{16}$ However, all the qualitative predictions remain the same as long as we assume a finite decision error. ${ }^{17}$ In particular, the rejection rate is decreasing in the offer size in all three conditions and it will never exceed 0.5. If responders face an offer of zero, their rejection is costless. Therefore the responders' rejection behavior is completely random, i.e., they reject with probability 0.5 . Rejections are costly for positive offers, so that the probability of rejections declines as offers increase. Differences in rejection behavior across treatments are most important for our purposes. Regardless of the (finite and constant) error parameter, QRE predicts that the rejection rate is lowest in the UG and highest in RC5. Thus the QRE approach with selfish preferences predicts the opposite comparative static results compared to the fairness approach.

\section{Figure 1 and Figure 2 about here}

The intuition behind the QRE prediction is that an increase in the number of competing responders increases the probability that at least one of the competitors will accept the offer. This means that the expected payoff for accepting the offer (which is identical to the expected cost of rejecting the offer) declines because there are more accepting responders. In other words, if the number of competing responders increases, the expected cost of rejecting the offer becomes smaller and, therefore, the rejection rate increases. The difference between the QRE approach and the fairness approach can also be illustrated in terms of the effect of the responders' beliefs about the other responders' rejection behavior. Recall that a fair responder is more likely to reject an offer if she believes that all the other responders will do likewise. In contrast, a selfish quantal response responder is less likely to reject the offer if she believes that all other responders will reject the offer because the rejection is more costly than if some of the other responders accept. Since we elicited

\footnotetext{
${ }^{16}$ Keeping the error parameter constant across conditions is important because by choosing different error parameters for different conditions, we could generate arbitrary comparative static results. The QRE approach would thus no longer generate refutable comparative static predictions. In a recent paper Haile, Hortaçsu and Kosenok (2008) show that any data set can be rationalized as a quantal response equilibrium unless one imposes a priori distributional assumptions on the model.

${ }^{17}$ More specifically, increasing $\mu$ simply stretches Figure 2 horizontally. For example, for an offer of 50, in our setting with $\mu=4$, we get the same value that we have for an offer of 100 and $\mu=8$.
} 
the responders' beliefs about the other responders' rejection behavior we are in a position to explicitly examine the impact of beliefs on responders' behavior.

Although the QRE approach with selfish preferences and the fairness approach make conflicting comparative static predictions with regard to responder behavior, their qualitative predictions with regard to proposer behavior are the same. Both approaches predict that the average accepted offer, denoted by $\hat{\mathrm{s}}$, obeys the order $\hat{s}^{U G}>\hat{s}^{R C 2}>\hat{s}^{R C 5}$. The reason for this is that the statistical effect, which is also present in the QRE approach, has a dominating effect on the proposers' rejection risk. Thus although each individual responder in responder competition is more likely to reject a low positive offer in, say, RC5 than in the UG, the probability that one of the five competing responders will accept the offer in RC5 is higher than the probability that the only responder will accept in the UG. Due to the lower rejection risk in RC5, the selfish proposers will, therefore, make lower offers on average.

For PC2, the responders' decision errors imply that they will sometimes reject both offers, in particular if they are low, and sometimes they will choose the lower of the two offers. For a given decision error, QRE unambiguously predicts that the proposers make higher offers in PC2 than in UG. This follows simply from the strong overbidding incentive inherent in PC2. Thus, like the fairness approach, QRE predicts $\hat{s}^{P C 2}>\hat{s}^{U G}$.

However, the fairness approach and the QRE approach make different quantitative predictions with regard to proposer behavior. This is most transparent in the UG and PC2. In the UG, the QRE approach implies that average offers of 30 or 40 are necessarily associated with many offers above 50 (see Figure 1), whereas the FS model predicts that there will be no offers above 50 because neither the selfish nor the inequity averse proposers will make such offers (see Table 1). In PC2, the fairness approach predicts that the proposers' offers will be very close to $s=100$, whereas the cumulative effects of noisy best reply behavior imply that the proposers' offers will be significantly below $s=100$, except in the case of extremely low decision errors. There are two reasons for this QRE prediction. First, due to decision errors, the responder will not always take the highest offer, which weakens the proposers' incentive to overbid. Second, the competing proposer puts positive probability on offers that are substantially below 100 due to decision errors. This creates an incentive for each proposer to make offers that are strictly below 100. Thus, the decision errors generate snowballing effects that drive the behavior away from the equilibrium derived under full rationality. 
In the following section we present our experimental results. This gives us the opportunity to address the strengths and the weaknesses of both approaches considered above. In this context, however, it is important to keep in mind that fairness and QRE approaches are not incompatible. It is possible to compute the players' expected utility of action $\mathrm{i}, u^{e}(i)$, under the assumption that a percentage of the players exhibits inequity averse preferences. It is an open question whether the mutual strengths or the mutual weaknesses of the two approaches reinforce each other in a combined QRE-Fairness model. In principle, it is possible that the poor predictions of each model may add up or that each of the models provides a correction for the other model's poor predictions. We defer the answer to this question until after the presentation of our experimental results.

\section{Experimental Results}

\section{A. The Effect of Competition on Accepted Offers}

In this section we examine the comparative static effects of competition on accepted offers. Recall that if subjects are selfish and rational, the average accepted offer should be less than or equal to one in the UG, RC2 and RC5. In PC2 they should be at least $\mathrm{s}=98$. Instead, we find the following:

RESULT 1: a) Introducing responder competition to the UG, by adding one extra responder, causes a large reduction in mean accepted offers. Adding three additional responders, by moving from $R C 2$ to $R C 5$, causes a further reduction in the mean accepted offer.

b) Introducing proposer competition to the $U G$, by adding one extra proposer, causes a large increase in mean accepted offers. However, proposers still reap a substantial share of the surplus.

The evidence for Result 1 is presented in Figure 3 and Tables 2 and 3. Figure 3 plots the evolution of average accepted offers in each treatment condition. It shows that responder and proposer competition both have strong impacts on accepted offers in the expected directions. Accordingly, mean accepted offers $\hat{s}$ obey the inequalities $\hat{s}^{P C 2}>\hat{s}^{U G}>\hat{s}^{R C 2}>\hat{s}^{R C 5}$ in every time period. It is also worth noting that there appear to be time trends in the competition treatments such that the gaps between the UG and the competition treatments appear to grow larger over time. These time trends 
appear smaller in the second half of the experiment than the first. In the final 8-10 periods the average offers remain fairly stable in PC2 and RC5. For example, the mean accepted offer in RC5 is 13.4 in period 10 and 13.8 in period 20. As we show below, regression analysis supports this observation (see Table 3$)^{18}$

Table 2 presents the means and standard deviations of the accepted offers. Columns 1-4 present average accepted offers by treatment for the 20 periods pooled; columns 5-8 present these averages for the final period. The first six rows present matching group averages. Row 7 pools the matching groups. Table 2 shows, again, that $\hat{s}$ obeys the inequality $\hat{s}^{P C 2}>\hat{s}^{U G}>\hat{s}^{R C 2}>\hat{s}^{R C 5}$. Rows 1-6 show that each matching group average in PC2 is substantially higher than the matching group averages in the UG. For example, in the sample that pools periods 1-20, the matching group averages in PC2 range from 63.3 to 76.1 while in the UG they range from 38.1 to 48 . In turn, the matching group averages are much higher in the UG than RC2. The differences between matching group averages in RC2 and RC5 are smaller, but by and large, accepted offers are larger in RC2: the smallest matching group average in $\mathrm{RC} 2$ is larger than three of the four matching group averages in RC5. The effect of competition on mean accepted offers is also clearly evident in row 7. It shows that the pooled average accepted offers for all periods and matching groups in PC2, UG, RC2 and RC5, are, respectively, 70.3, 42.7, 25.5 and 16.2. In the final period, the pooled average for all matching groups in PC2, UG, RC2 and RC5 are, respectively, 77.8, 41.1, 18.8 and 13.8.

Table 2 also suggests time trends in the competition treatments. Within matching groups, final period averages in PC2 are higher than averages for the whole 20 periods while final period averages for RC2 and RC5 are lower. Averages in the UG do not change clearly over time. This result is also evident in row 7 which pools the matching groups: compared to the pooled averages for the whole 20 periods, the averages in the final period are higher in PC2, lower in RC2 and RC5, and roughly the same in the UG.

\section{Figure 3 and Table 2 about here}

Using matching group averages as independent units of observation, we test these treatment differences with Mann-Whitney tests. According to these tests, the UG differs significantly from PC2 and RC2 ( $p=.005$ in both cases). Likewise, the mean accepted offers in RC5 are significantly

\footnotetext{
${ }^{18}$ In Figure 3 and the regressions below, we expect the time trend to be in the direction of the theoretical prediction, which differs across treatments. Thus, our regressions below will include interactions between the time trend and the treatment dummies to allow the time trend to differ across treatments.
} 
lower than in $\mathrm{RC} 2(p=.028)$. The null hypothesis that there is no trend across treatments is rejected at all conventional significance levels $(\mathrm{p}<.001)$ by a non-parametric trend test (nptrend test). ${ }^{19}$ Using matching group averages from the last period only, we find that accepted offers in the UG are significantly different from accepted offers in each of the other treatments at the five percent level; accepted offers in RC2 and RC5 are not significantly different from each other at conventional significance levels $(\mathrm{p}=.148)$; and the nptrend test is significant at the one-percent level $(\mathrm{p}<.001)$.

Table 3 presents regressions of the mean accepted offer on the time period and interactions between the treatment dummies and the time period. The first and second columns pool the four treatments, with the UG as the omitted category. The third and fourth columns pool RC2 and RC5, with RC2 as the omitted category. The first and third columns pool all 20 time periods. The second and fourth columns pool the final 10 periods. We number the time periods from -19 to zero in the first and the third regression, and from -9 to zero in the second and fourth regression, so that the reported coefficients represent effects in the final time period. For all of our regressions, we present bootstrapped standard errors that allow for correlated errors within matching groups. ${ }^{20}$

Column 1 of Table 3 shows that the estimated accepted offer in the final time period of the UG is 42.7. The large and highly significant coefficients for PC2, RC2, and RC5 show that the estimated accepted offers in the competition treatments differ substantially, in the expected directions, from that in the UG. The coefficient for RC5 in column 3 indicates that the estimated accepted offer in RC5 is 7.5 units lower than in RC2. Columns 2 and 4 show that, controlling for time trends the treatment differences in the final 10 periods are not substantially different from the treatment differences in the whole 20 periods.

Table 3 shows little change over time in the UG offers. The estimated coefficient on the variable "time period" is close to zero and insignificant in columns 1 and 2 . In column 1 which uses all 20 periods of data, the interactions between "time period" and PC2, RC2 and RC5 are significant at the 5 percent level or better. In column 2 which uses the final 10 periods of data, the interactions between "time period" and the competition treatment dummies are smaller and no longer significant at the 5 percent level. Columns 3 and 4 show that the time trend in RC2 is significant both in all 20 periods and the final 10 periods. However, the magnitude of the effect in the final 10 periods is roughly $50 \%$ smaller.

\footnotetext{
${ }^{19}$ The nptrend test takes the order between the treatments into account (see Cuzick 1985) and is thus the appropriate test for examining our comparative static results. It is an extension of the Wilcoxon rank sum test.

${ }^{20}$ We draw bootstrap samples of entire matching groups and compute standard errors that allow for correlated error within matching groups, with roughly 1000 replications.
} 
To check the sensitivity of the Table 3 results for the second half of the game, we also estimated the results for the final 11 and the final 9 periods (not reported). The differences in offers between the UG and the each of the other treatments are highly significant in the final 11,10 , and 9 periods of the game, respectively. In regressions using data from RC2 and RC5 only, the treatment effect is marginally significant in each sample ( $p$-values ranging from .072 to .106). Examining time trends within each treatment for the final 11, 10 and 9 periods, respectively, we find no significant time trends in the $\mathrm{UG}$ or RC5. The time trend in RC2 is significant at the one-percent level in all three samples. The time trend in PC2 is significant at the five and ten-percent levels in the final 11 and 10 periods, respectively, and insignificant in the final 9 periods. Thus, the results that appear robust in the second half of the game are effects of the competition treatments compared to the $\mathrm{UG}$ and a time trend in $\mathrm{RC} 2$.

\section{Table 3 about here}

Our results show that both the FS and QRE models correctly predict the qualitative changes in the mean offers across treatments, i.e. they predict $\hat{S}^{P C 2}>\hat{s}^{U G}>\hat{s}^{R C 2}>\hat{s}^{R C 5}$. The FS prediction of the average accepted offer for the $\mathrm{UG}$ and RC2 in Table 1 is also remarkably precise in quantitative terms. The predicted values are 43.4 and 17.0, respectively; the actual values in the final period (see Table 2) are 41.1 in the UG and 18.8 in RC2. However, both the FS model and the QRE model predict some quantitative details of the data incorrectly. In the UG roughly 70 percent of all offers are between 40 and 50 and almost no offers are above 50. However, as Figure 1 indicates, the QRE model is not capable of rationalizing this result: It predicts average offers at or above 40 only at the cost of very large decision errors that imply a large percentage of offers above 50. In contrast, the FS model predicts this aspect of the data correctly. However, it over-predicts the quantitative impact of proposer competition in PC2.

\section{B. The Effect of Competition on Proposers' Rejection Risk}

The previous section showed that merely introducing competition to the UG has large effects on accepted offers. Toward the end of the session, the responder's earnings in PC2 are almost twice as large as in the $\mathrm{UG}$, while the trading responder in $\mathrm{RC} 2$ receives only $50 \%$ of the responder's share in the UG. Why does introducing a single competitor to the UG cause such an unequal distribution of payoffs, despite the fact that many other experiments have demonstrated the existence of a large number of fairness seeking subjects? According to the fairness and the QRE approaches discussed

in Section III, responder competition reduces the rejection risk that the proposers face, enabling 
them to reap lower accepted offers. In addition, the fairness approach predicts that fewer proposers will be willing to share the gains from trade equally with the trading responder because it requires a stronger fairness motivation to do so under responder competition. Only highly fairness-seeking proposers will be willing to share the gains from trade equally under responder competition. Both the fairness and the QRE approaches also predict that the rejection risk is greater in PC2 than the $\mathrm{UG}$, which induces the proposers to increase their offers relative to the UG

Our next result shows that the data nicely confirm these predictions regarding the rejection risk.

RESULT 2: a) Introducing responder competition, by moving from the $U G$ to $R C 2$, causes a large reduction in the proposers' rejection risk. Adding three additional responders by moving from $R C 2$ to RC5 causes a further significant reduction of the rejection risk. The money-maximizing offer is, therefore, much lower in responder competition than the UG.

b) Introducing proposer competition, by moving from the UG to PC2, causes a large increase in the proposers' rejection risk, moving the money maximizing offer far above those in the UG.

Support for Result 2 is presented in Figure 4 and Table 4. Figure 4 plots the proposer's rejection risk against the size of the offer. The proposer's rejection risk for a given offer is defined by the number of such offers that all responders reject divided by the total number of such offers proposers make. We find that the rejection risk declines dramatically when we move from the UG to RC2. For instance, while the rejection risk for offers below 25 is between 80 and 100 percent in the UG, the risk for the same offer range varies between 5 and 50 percent in RC2. Figure 4 shows a further substantial decline in the rejection risk if five instead of two responders compete with each other. The rejection risk strongly increases in PC2 relative to the UG, although the rejection risk is far below 100 percent for offers above 50. The rejection risk in PC2 obviously depends not only on the responder's behavior but on that of the competing proposer as well.

Figure 4 and Table 4 about here 
Table 4 presents probit analyses predicting whether or not a proposer's offer is rejected by all responders. ${ }^{21}$ The independent variables are the size of the offer, the treatment, the time period, and interaction terms for each treatment and the time period. The first regression pools all treatments and all periods. The second regression pools the responder competition treatments and all time periods. The probit coefficients on the offer are negative and significant, at the $1 \%$ and $5 \%$ levels, in both regressions. The associated marginal effects (at the sample means), presented in columns 2 and 4, indicate that an increase in the offer by 10 units decreases the rejection risk by 14 percent in the first column and by 4 percent in the second column. The coefficients on PC2, RC2, and RC5 are also highly significant. Controlling for the size of the offer, the time period, the treatment, and interactions between the treatments and time period, the predicted probability of an offer being rejected is 29.1 percent lower in RC2, 38.3 percent lower in RC5, and 79 percent higher in PC2 than in the UG. The second regression shows that there is also a significant difference between RC5 and RC2. The predicted probability - evaluated at the average offer and time period - of an offer being rejected in $\mathrm{RC} 5$ is 9 percent smaller than in $\mathrm{RC} 2{ }^{22}$

The large reduction in the proposers' rejection risk is associated with large changes in the expected payoff. In Figure 5 we present the proposers' expected payoff as a function of the offer size across all four treatments. The expected payoff in the UG is maximized at $s=50$ but the payoff loss is very small for offers slightly below 50 . The peak of the expected payoff is at much lower offer levels in both RC2 and RC5. The expected payoff in RC2 is maximized at $s=5$ but the payoff is only slightly lower at $s=20$. In addition, the very high payoff at $\mathrm{s}=5$ could well be an artifact of the small number of observations. Offers of $s=5$ occurred only in 4 percent of the cases in RC2, whereas 21 percent of all offers are at $s=20$. In RC5, however, the peak at $s=5$ is surely not an artifact because 33 percent of all offers are at $s=5$. In fact, an offer of $s=5$ is the mode in RC5. The expected payoff in PC2 is maximized at offers of 65 and $700^{23}$

Figure 5 about here

\footnotetext{
${ }^{21}$ As in Table 3 all standard errors allow for arbitrary error correlations of observations within matching groups and only observations across matching groups are treated as independent.

${ }^{22} \mathrm{We}$ do not have enough rejection data to estimate Table 4 with the final 10 periods of data. However, since there may be large learning effects at the beginning of the experiment, we checked the sensitivity of the results to dropping the first two periods of data. The results of column 1 are very similar when estimated using the last 18 periods of data. In the second column, the time period in RC5 no longer has a significant effect when the first two periods of data are dropped.

${ }^{23}$ In PC2 offers at s $=50$ are almost as profitable as those of 65 and 70 . However, this could also be an artefact of the small number of observations at $\mathrm{s}=50$.
} 
The large differences in the money maximizing offer across treatments provide an explanation for the large differences in proposers' behavior across treatments. In fact, the majority of the proposers' offers are in the vicinity of the money maximizing offer in all four treatments. In the final 10 periods, 69.1 percent of all offers in the UG are in the interval $[40,50]$; 61 percent of the offers in PC2 are in the interval [60, 80]; 66.9 percent of the offers in RC2 are in the interval $[15,25]$ and 79.5 percent of the offers in RC5 are in the range $[5,15]$. In section $\mathrm{V}$, we will show that a combination of the FS and the QRE model explains these aspects in the distribution of offers quite well.

There is one interesting quantitative feature in Figure 4 which explains why the pure FS model overpredicts the change in the proposers' behavior if one introduces proposer competition. According to the FS model (and the self-interest model with full rationality), the rejection risk for offers below $s=98$ is 100 percent in PC2. In fact, however, the rejection risk is considerably below 100 percent in the interval [50, 97]; for offers above 90 it is even zero. This means that the proposers had an incentive to move away from the predicted equilibrium offers in the range [98, $100]$.

\section{The Effect of Responder Competition on Responder Behavior}

The fairness approach implies that the reduction in the proposers' rejection risk in RC2 and RC5 is a consequence of heterogeneous fairness preferences among the responders and the behavioral changes which competition induces among the responders. Recall that preference heterogeneity among the responders means that the proposers face a distribution of acceptance thresholds. This, in turn, implies that the probability that all responders will reject a given offer declines if the number of responders increases. We have called this the statistical effect because it prevails even if responders do not change their rejection behavior when additional competitors are added. However, one of the salient predictions of the fairness approach and the QRE approach is that responders will change their rejection behavior across treatments and that the responders' beliefs about the other responders' rejection behavior is the driving force behind these changes. Moreover, the fairness approach and the QRE approach make opposing predictions with regard to the changes in responders' behavior. Therefore, we examine next whether and how the responders changed their rejection behavior in the face of additional competition. 
RESULT 3: Introducing responder competition, by moving from the UG to RC2, causes a substantial reduction in individual responders' willingness to reject. A further increase in competition by moving to RC5 causes an additional significant reduction in the willingness to reject. The changes in responders' rejection behavior across treatments can be explained by the belief effect.

The evidence for Result 3 is presented in Figures 6 and 7 and Tables 5 and 6 . In Figure 6, we show the rejection behavior from the responders' perspective. We plot the responder's rejection rate against the size of the offer. The rejection rate is measured by the number of responders who rejected an offer divided by the total number of responders who received the corresponding offer. The rejection rate in the UG is 100 percent for any offer below 10, i. e., all responders reject such offers. This means that the statistical effect cannot become operative in this offer range unless responder competition reduces some responders' willingness to reject. Therefore, the large reduction in the proposers' rejection risk (in this offer range) observed in Figure 4 is based on the behavioral changes responder competition induces: the responders' rejection rate for offers below 10 is much lower in RC2 and RC5 than in the UG, and varies between 50 and 78 percent (see Figure 6). In all three treatments, the responder's rejection rate decreases in the size of the offer, but this decrease already occurs for offers below 10 in RC2 and RC5. The rejection rate in RC2 for all offer intervals below 40 is at least 20 percent lower than in the UG. Moreover, the rejection rate in RC5 is lower than in RC2 for most offer intervals.

Column 1 of Table 5 provides further support for Result 3. Table 5 presents coefficients from a probit regression predicting responders' rejections. The independent variables are the offer size, dummies for RC2 and RC5 (UG is the omitted category), the time period, and interactions between the treatment dummies and the time period. The regression shows that the coefficients on offer size and the treatment dummies for RC2 and RC5 are all negative and highly significant. The associated marginal effects indicate that at the sample means, the rejection probability is 27 percent lower in $\mathrm{RC} 2$ than in the UG. The rejection rate (at sample means) in RC5 is a striking 53 percent lower than in the UG. Thus, the treatment differences observed in Figure 6 are clearly substantial and 
statistically significant. ${ }^{24}$ These treatment differences contradict the QRE approach and are consistent with the predictions of the fairness approach.

\section{Figure 6 and Figure 7 about here}

\section{Table 5 and Table 6 about here}

Since the fairness approach not only predicts a reduction in the rejection rate under responder competition but also identifies responders' beliefs as the decisive source of this behavioral change, we introduced a belief measure into our regression. Recall that in both responder competition treatments, responders reported their beliefs about how many other responders would accept the going offer. This enables us to create a dummy variable that equals one if the responder believes that all other responders will reject the offer and zero otherwise. We refer to this dummy variable as "belief that all others reject" and, in Table 6, add it to the specification presented in Table 5. If a responder believes that all others reject, then she considers herself a decisive player in the sense that she can punish the proposer or maintain equity by rejecting the offer too. Thus, the fairness approach predicts that this variable has a positive effect on rejection rates. The coefficient on the offer size is again negative and significant. The "all others reject" dummy is positive, highly significant, and implies a high marginal effect. If a responder believes she is decisive, her rejection rate increases by 37.4 percent. Moreover, the treatment dummies for RC2 and RC5 are now insignificant and rather small relative to the regression in Table 5, suggesting that the treatments per se have little or no effect on rejection behavior if we control for the belief effect. This interpretation is further supported by the second regression in Table 6 where we use only the RC2 and the RC5 data. The "all others reject" dummy is again large and significant, indicating an increase in the rejection probability of 41 percent if a responder believes that all others reject, and the treatment dummy for RC5 is close to zero and insignificant. Thus, again the treatment per se has no effect on the rejection behavior if we control for the responders' beliefs. ${ }^{25}$

Recall that the statistical effect on proposers' rejection risk is based on the presence of heterogeneous responders. To examine responder heterogeneity, we ran probit regressions for each treatment separately in which we included the offer size, time period, and dummies for individual

\footnotetext{
${ }^{24}$ In an unreported robustness check, we estimated the specification of Table 5 using the final 18 periods of data. The noteworthy differences are that the time period and the interaction between RC5 and the time period are smaller and statistically insignificant in the final 18 periods.

${ }^{25}$ In an unreported robustness check, we estimated the specifications of Table 6 using the final 18 periods of data. The noteworthy difference is that the statistical significance of the time period coefficients falls somewhat in both regressions. The time period coefficient is significant at the ten percent level in both regressions in the final 18 periods.
} 
responders. We observed strong evidence for responder heterogeneity in each treatment. Likelihood ratio tests for the joint significance of the individual dummies show that the restricted model (with no individual dummies) is significantly different from the model with individual dummies at all conventional significance levels ( $\mathrm{p}<.0001$ in each treatment).

The effect of beliefs on rejection behavior is so strong that it can even be detected in the raw data. In Figure 7, we illustrate the responders' rejection probability in RC2 for the case in which the responder believes that the competitor rejects and for the case in which she believes that the competing responder accepts. As one can see, the rejection probability is much higher if the responder believes that the competitor will also reject the offer. Thus, taken together Figures 6 and 7 and the regressions in Tables 5 and 6 provide strong support for the fairness approach because they suggest that the belief effect is the major determinant of the changes in rejection behavior across treatments.

\section{Combining the Fairness Approach with the QRE Approach}

Our data show that both the fairness model and the QRE model with selfish preferences correctly predict the qualitative changes in accepted offers across treatments. The introduction of responder competition reduces the mean accepted offers substantially; increasing responder competition from two to five responders causes a further reduction in mean accepted offers; and the introduction of proposer competition increases the mean accepted offers substantially.

Several quantitative aspects of the data suggest, however, that each of these models alone cannot capture all of the important phenomena at work. In proposer competition, the fairness model over-predicts the change in accepted offers, because it over-predicts the proposers' rejection risk. This suggests that we need more than the assumption of heterogeneous fairness preferences to explain these facts. One needs a model that explains the relatively low rejection risk for the proposers when they make offers that give them a sizeable share of the pie. As we explained in Section III, the QRE model provides a natural explanation for this phenomenon.

However, the QRE approach with selfish preferences predicts the wrong comparative static effects of responder competition on responders' behavior. In contrast to the QRE prediction, the introduction of or an increase in responder competition reduces the responders' rejection rate (compare Figure 2 with Figure 6). In addition, the QRE approach under-predicts the rejection rate 
for low offers in the UG and the responder competition treatments and over-predicts the existence of offers above 50 in the UG. Recall that the predicted rejection rate can never exceed 50 percent according to the QRE approach (see Figure 2), while the actual rejection rate is between 75 and 100 percent for offers between 0 and 4 in the UG, RC2 and RC5. The fairness approach provides a natural explanation for these phenomena. In addition, it captures the major driving force behind the reduced rejection rate in responder competition: the belief that one of the competing responders will accept the offer.

Our discussion above suggests, therefore, that we need both heterogeneous fairness preferences and decision errors to explain all of the important phenomena that shape the effects of competition in our treatments. In principle, the QRE approach can be combined with fairness preferences. However, there is no guarantee that the combination of the fairness and the QRE approaches will not mutually reinforce the weaknesses of each approach. To check the performance of a combined model, we computed the distribution of equilibrium actions of a fully parameterized FS-QRE model. For this purpose, we completely tied our hands with regard to the choice of the parameters for the FS model by using the same preference parameters as in Fehr and Schmidt (1999) which are presented in Table 1. This is very important because otherwise we may be able to rationalize too many different outcomes by choosing the appropriate preference parameters. Therefore, the only free parameter was the error parameter $\mu$ from the QRE part of the model.

We estimate $\mu$ by maximizing the likelihood of the offer distributions across all four experimental treatments. ${ }^{26}$ This means that the same preference and error parameters are applied to all treatments in order to generate the prediction. ${ }^{27}$ Because we employ an equilibrium model to

\footnotetext{
${ }^{26}$ For each $\mu$, we calculated QRE in the following way: We start with an offer distribution and a vector of rejection probabilities. Then, we calculate quantal best replies for each of the four FS types. Using the assumed frequencies of the FS types $(30 \%, 30 \%, 30 \%, 10 \%)$, we get a new distribution of offers and rejection probabilities. If this new distribution equals the initial distribution, i.e., if the newly calculated distribution of offers and the rejection probabilities differ only slightly (in total, by $10^{-12}$ ) form the initial distribution, we have found the solution. If not, we replace the old distribution with this newly calculated distribution of offers and the rejection probabilities. When the algorithm does not converge, we replace the old distribution with a weighted average of the old distribution and the newly calculated distribution. With a suitable weight, the algorithm always converged.

${ }^{27}$ The error parameter is given by Swiss francs (CHF). In the combined model, it is CHF 0.236, in the pure QRE model, it is CHF 0.478. Since we set the same error parameter across conditions in terms of CHF, we assumed that money illusion does not affect subjects' behavior in our environment. Note that a constant error parameter in terms of CHF implies that the error parameter in terms of experimental money varies because the exchange rate between Swiss francs and experimental money units differs across conditions (in order to keep the gains from trade per player constant across conditions). For example, an error parameter of CHF 0.236 implies that the error parameter in terms of experimental money units is 3.3 in RC5, 6.6 in RC2, 9.8 in the UG, and 6.6 in PC2. Likewise, a constant error parameter in terms of experimental money units implies that the error parameter in terms of CHF varies across conditions.
} 
predict behavior, we use the final 10 periods of data, where a more stable behavioral pattern had emerged (i.e., where there was relatively little change in the distribution of offers). We perform the calculation for the combined FS-QRE model and the pure QRE model.

In Figure 8, we show the predicted equilibrium distribution of offers across all four treatments. For each treatment, we show the cumulative distribution of the actual offers, the predicted offers from the combined FS-QRE model, the predicted offers from the pure QRE model, and the predicted offers from the pure FS model. In the RC2 and RC5 treatments this prediction is not unique. In these cases, we show the highest possible equilibrium.

The ultimatum game panel of Figure 8 reveals that the pure FS model and the combined model both fit the UG data very well. The success of the pure FS model merely shows that we replicate previous findings about the ultimatum game, because Fehr and Schmidt chose a distribution of parameters that was consistent with ultimatum game data. The pure QRE model needs a rather high error parameter to generate higher offers, which makes the distribution too broad. The RC2 and RC5 panels of Figure 8 show that the QRE and combined FS-QRE models both make good predictions in responder competition. These predictions replicate the actual comparative static differences between the three treatments, and they are remarkably close to the actual distribution. In the responder competition games, the pure FS model makes a qualitatively good prediction which is, however, not very precise. ${ }^{28}$ QRE and the combined model on the other hand make more precise predictions. Finally, the PC2 results can only be captured by the combined model. QRE predicts a variance that is too high and the pure FS model makes the excessively extreme prediction that all players make an offer of at least 98.

\section{Figure 8 about here}

We conclude with a statistical evaluation of the data based the log likelihood. ${ }^{29}$ Since the parameters of the FS-model are exogenously fixed, we can directly compare the log likelihood of the combined FS-QRE model with the pure QRE model. The individual observations are not

\footnotetext{
${ }^{28}$ The FS model predicts too high offers in the responder competition games. Note, however that we used the FSequilibrium with the highest offers in the construction of Figure 8.

${ }^{29}$ Since the pure FS model makes $0 / 1$ predictions for many offers, it has a likelihood of 0 and cannot be evaluated with this test.
} 
independent, so we used a bootstrap method: We sampled matching groups with replacement and performed the log likelihood optimization as described above. We drew 100 samples and in each of the samples the log likelihood was higher in the combined FS-QRE model than the pure QRE model. Thus, also from a statistical point of view, this model has to be preferred over the pure QRE model.

\section{Conclusions}

The main message of this paper is that basic economic effects of competition cannot be understood without taking fairness concerns and decision errors into account. To support this claim, we conducted a series of experiments and developed an alternative to the prevailing model that takes both fairness and decision errors into account. The prevailing model fails to capture the powerful effects of adding just one additional responder to a bilateral ultimatum game. In the case of proposer competition, the model makes the opposite error: it over-predicts the changes in accepted offers. In contrast, our combined fairness and quantal response equilibrium model correctly predicts all qualitative changes associated with increased competition and provides a good quantitative characterization of the entire distribution of accepted offers. In view of these results, we believe that the combined fairness-QRE model may generally improve our understanding of the mechanisms through which competition affects bargaining. 


\section{References}

Anderson, S., Goeree. J. and Holt C., 1998. The all-pay auction: equilibrium with bounded rationality. Journal of Political Economy 106, 828-853.

Bolton, G. and Ockenfels, G., 2000. ERC: a theory of equity, reciprocity and competition. American Economic Review 90, 166-193.

Becker, G., 1962. Irrational behavior and economic theory. Journal of Political Economy 70, 113.

Brandts, J., and Charness, G., 2004. Do labour market conditions affect gift exchange? Some experimental evidence. Economic Journal 114, 684-708.

Camerer, C., 2003. Behavioral Game Theory - Experiments in Strategic Interaction. Princeton: Princeton University Press.

Charness, G. and Rabin, M., 2002. Understanding social preferences with simple tests. Quarterly Journal of Economics 117, 817-869.

Dufwenberg, M. and Kirchsteiger, G., 2004. A theory of sequential reciprocity. Games and Economic Behavior 47, 268-98.

Falk, A. and Fischbacher, U., 2006. A theory of reciprocity. Games and Economic Behavior 54, 293-315.

Fehr, E., Kirchsteiger, G., and Riedl, A., 1999. Does fairness prevent market clearing? Quarterly Journal of Economics 108, 437-459.

Fehr, E., and Falk, A., 1999. Wage rigidity in a competitive incomplete contract market. Journal of Political Economy 107, 106-134.

Fehr, E. and Schmidt, K., 1999. A theory of fairness, competition and cooperation. Quarterly Journal of Economics 114, 817-868.

Fehr, E., Schmidt, K., 2003. Theories of fairness and reciprocity - evidence and economic applications. In: Dewatripont, M., Hansen, L., and Turnovsky, S. (Eds.). Advances in Economics and Econometrics: Theory and Applications, 8th World Congress, Volume 1, Econometric Society Monographs. Cambridge University Press.

Fischbacher, U. 2007, z-Tree: Zurich toolbox for ready-made economic experiments. Experimental Economics 10, 171-178.

Goeree, J. K. and Holt, C. A., 2000. Asymmetric inequality aversion and noisy behavior in alternating-offer games. European Economic Review 44, 1079-1089.

Goeree, J. K. and Holt, C. A., 2001. Ten little treasures of game theory and ten intuitive contradictions. American Economic Review 91, 1402-1422.

Goeree, J. K. and Holt, C. A., and Laury, S. K., 2002. Private costs and public benefits: unraveling the effects of altruism and noisy behavior. Journal of Public Economics 83, 255276.

Goeree, J. K., Holt, C. A., and Palfrey, T. R, 2002. Quantal response equilibrium and overbidding in private-value auctions. Journal of Economic Theory 104, 247-272. 
Grosskopf, B., 2003. Reinforcement and directional learning in the ultimatum game with responder competition. Experimental Economics 6, 141-158.

Güth, W., Schmittberger R., and Schwarze B., 1982. An experimental analysis of ultimatum bargaining. Journal of Economic Behavior and Organization 3, 367-388.

Güth, W., Marchand, N. and Rullière, J.L., 1998. Equilibration and context-dependency: an experimental investigation of the ultimatum bargaining game. Revue Economique 49, 785794.

Güth, W., and Tietz, R., 1990. Ultimatum bargaining behavior - a survey and comparison of experimental results. Journal of Economic Psychology 11, 417-449.

Haile, P. A., Hortacsu A. and Kosenok G., 2008. On the empirical content of quantal response equilibrium. The American Economic Review 98, 180-200.

Levine, D., 1998. Modeling altruism and spitefulness in experiments. Review of Economic Dynamics 1, 593-622.

McKelvey, R. and Palfrey, T., 1995. Quantal response equilibria for normal form games. Games and Economic Behavior 10, 6-38.

Rabin, M., 1993. Incorporating fairness into game theory. The American Economic Review 83, 1281-1302.

Roth, A., 1995. Bargaining experiments. In Kagel, J., and Roth, A. (Eds.). The Handbook of Experimental Economics. Princeton: Princeton University Press.

Roth, A., Prasnikar, V., Okuno-Fujiwara, M. and Zamir, S., 1991. Bargaining and market behavior in Jerusalem, Ljubljana, Pittsburgh, and Tokyo: an experimental study. American Economic Review 81, 1068-1095.

Smith, V. L., 1962. An experimental study of competitive market behavior. Journal of Political Economy 70, 111-137.

Smith, V. L., 1982. Microeconomic systems as an experimental science. American Economic Review 72, 923-955. 


\section{TABLE 1}

Prediction of offers and acceptance thresholds under responder competition based on the preference parameters of Fehr and Schmidt (1999)

\begin{tabular}{|c|c|c|c|c|c|c|}
\hline \multirow{2}{*}{\multicolumn{2}{|c|}{$\begin{array}{l}\text { Preference } \\
\text { parameters } \\
\text { Relative } \\
\text { frequency }\end{array}$}} & \multirow{2}{*}{$\begin{array}{c}\alpha=4, \beta=.6 \\
10 \%\end{array}$} & \multirow{2}{*}{$\begin{array}{c}\alpha=1, \beta=.6 \\
30 \%\end{array}$} & \multirow{2}{*}{$\begin{array}{c}\alpha=.5, \beta=.25 \\
30 \%\end{array}$} & \multirow{2}{*}{$\begin{array}{c}\alpha=0, \beta=0 \\
30 \%\end{array}$} & \multirow[t]{2}{*}{$\begin{array}{c}\text { average } \\
\text { accepted } \\
\text { offer }\end{array}$} \\
\hline & & & & & & \\
\hline \multirow[t]{3}{*}{ Offers } & UG & 50 & 50 & 44 & 33 & 43.4 \\
\hline & $\mathrm{RC} 2$ & 17 & 17 & 17 & 17 & 17.0 \\
\hline & RC5 & 4 & 4 & 4 & 4 & 4.0 \\
\hline \multirow[t]{3}{*}{$\begin{array}{l}\text { Acceptance } \\
\text { thresholds }\end{array}$} & $\mathrm{UG}$ & 44 & 33 & 25 & 0 & \\
\hline & $\mathrm{RC} 2$ & 17 & 17 & 15 & 0 & \\
\hline & RC5 & 4 & 4 & 4 & 0 & \\
\hline
\end{tabular}


TABLE 2

Mean accepted offers

\begin{tabular}{|c|c|c|c|c|c|c|c|c|}
\hline \multirow[b]{2}{*}{$\begin{array}{c}\text { Matching } \\
\text { group }\end{array}$} & \multicolumn{4}{|c|}{ All Periods } & \multicolumn{4}{|c|}{ Final Period } \\
\hline & $\begin{array}{c}\text { PC2 } \\
\text { mean } \\
\text { (s.d.) }\end{array}$ & $\begin{array}{c}\mathrm{UG} \\
\text { mean } \\
\text { (s.d.) }\end{array}$ & $\begin{array}{c}\mathrm{RC} 2 \\
\text { mean } \\
\text { (s.d.) }\end{array}$ & $\begin{array}{l}\text { RC5 } \\
\text { mean } \\
\text { (s.d.) }\end{array}$ & $\begin{array}{l}\text { PC2 } \\
\text { mean } \\
\text { (s.d.) }\end{array}$ & $\begin{array}{c}\mathrm{UG} \\
\text { mean } \\
\text { (s.d.) }\end{array}$ & $\begin{array}{l}\mathrm{RC} 2 \\
\text { mean } \\
\text { (s.d.) }\end{array}$ & $\begin{array}{l}\text { RC5 } \\
\text { mean } \\
\text { (s.d.) }\end{array}$ \\
\hline 1 & $\begin{array}{c}67.7 \\
(10.2)\end{array}$ & $\begin{array}{l}43.2 \\
(7.8)\end{array}$ & $\begin{array}{c}26.4 \\
(17.4)\end{array}$ & $\begin{array}{l}13.6 \\
(8.9)\end{array}$ & $\begin{array}{l}71.5 \\
(4.4)\end{array}$ & $\begin{array}{l}45.5 \\
(4.2)\end{array}$ & $\begin{array}{c}14.3 \\
(15.4)\end{array}$ & $\begin{array}{c}12.0 \\
(12.4)\end{array}$ \\
\hline 2 & $\begin{array}{c}63.3 \\
(12.0)\end{array}$ & $\begin{array}{l}44.2 \\
(8.4)\end{array}$ & $\begin{array}{l}23.5 \\
(8.6)\end{array}$ & $\begin{array}{c}23.5 \\
(20.0)\end{array}$ & $\begin{array}{l}76.7 \\
(6.7)\end{array}$ & $\begin{array}{l}46.5 \\
(4.7)\end{array}$ & $\begin{array}{l}18.0 \\
(8.5)\end{array}$ & $\begin{array}{c}21.3 \\
(22.5)\end{array}$ \\
\hline 3 & $\begin{array}{c}72.6 \\
(17.4)\end{array}$ & $\begin{array}{l}39.7 \\
(4.0)\end{array}$ & $\begin{array}{c}29.6 \\
(15.7)\end{array}$ & $\begin{array}{c}17.1 \\
(14.9)\end{array}$ & $\begin{array}{l}73.0 \\
(2.9)\end{array}$ & $\begin{array}{l}40.0 \\
(0.0)\end{array}$ & $\begin{array}{c}25.3 \\
(13.4)\end{array}$ & $\begin{array}{c}14.0 \\
(10.7)\end{array}$ \\
\hline 4 & $\begin{array}{c}76.1 \\
(13.4)\end{array}$ & $\begin{array}{c}48.0 \\
(10.7)\end{array}$ & $\begin{array}{c}22.3 \\
(10.0)\end{array}$ & $\begin{array}{l}10.9 \\
(8.8)\end{array}$ & $\begin{array}{l}89.8 \\
(0.5)\end{array}$ & $\begin{array}{c}37.7 \\
(14.3)\end{array}$ & $\begin{array}{l}17.8 \\
(3.3)\end{array}$ & $\begin{array}{c}7.8 \\
(2.1)\end{array}$ \\
\hline 5 & & $\begin{array}{l}42.4 \\
(6.2)\end{array}$ & & & & $\begin{array}{l}42.0 \\
(7.0)\end{array}$ & & \\
\hline 6 & & $\begin{array}{l}38.1 \\
(8.7)\end{array}$ & & & & $\begin{array}{l}31.7 \\
(2.9)\end{array}$ & & \\
\hline Mean & $\begin{array}{c}70.3 \\
(14.4)\end{array}$ & $\begin{array}{l}42.7 \\
(8.6)\end{array}$ & $\begin{array}{c}25.5 \\
(13.7)\end{array}$ & $\begin{array}{c}16.2 \\
(14.5)\end{array}$ & $\begin{array}{l}77.8 \\
(8.4)\end{array}$ & $\begin{array}{l}41.1 \\
(7.8)\end{array}$ & $\begin{array}{c}18.8 \\
(10.8)\end{array}$ & $\begin{array}{c}13.8 \\
(13.5)\end{array}$ \\
\hline
\end{tabular}

Note: Standard deviations are in parentheses. PC2 denotes the market game with two competing proposers. UG denotes Ultimatum Game, RC2 denotes the market game with two competing responders, RC5 denotes the market game with 5 competing responders. 
TABLE 3

Pooled regressions predicting accepted offers

\begin{tabular}{|c|c|c|c|c|}
\hline & \multicolumn{4}{|c|}{ Dependent variable: accepted offer } \\
\hline & \multicolumn{2}{|c|}{$\begin{array}{l}\text { PC2, UG, RC2, and RC5 } \\
\text { Pooled }\end{array}$} & \multicolumn{2}{|c|}{ RC2 and RC5 Pooled } \\
\hline & all periods & $\begin{array}{l}\text { final } 10 \\
\text { periods }\end{array}$ & all periods & $\begin{array}{l}\text { final } 10 \\
\text { periods }\end{array}$ \\
\hline PC2 & $\begin{array}{l}35.334^{* * *} \\
(6.563)\end{array}$ & $\begin{array}{c}34.301^{* * *} \\
(6.444)\end{array}$ & & \\
\hline PC2*time period & $\begin{array}{c}0.817 * * \\
(0.393)\end{array}$ & $\begin{array}{l}0.686^{*} \\
(0.366)\end{array}$ & & \\
\hline $\mathrm{RC} 2$ & $\begin{array}{l}-24.167 * * * \\
(3.715)\end{array}$ & $\begin{array}{l}-22.366^{* * * *} \\
(3.466)\end{array}$ & & \\
\hline $\mathrm{RC} 2 *$ time period & $\begin{array}{l}-0.753^{* * *} \\
(0.227)\end{array}$ & $\begin{array}{l}-0.237 \\
(0.203)\end{array}$ & & \\
\hline RC5 & $\begin{array}{l}-31.616^{* * * *} \\
\quad(4.851)\end{array}$ & $\begin{array}{l}-28.994 * * * \\
(4.383)\end{array}$ & $\begin{array}{l}-7.449 \\
(4.301)\end{array}$ & $\begin{array}{l}-6.628^{*} \\
(3.678)\end{array}$ \\
\hline RC5*time period & $\begin{array}{c}-0.539 * * * \\
(0.192)\end{array}$ & $\begin{array}{c}0.050 \\
(0.196)\end{array}$ & $\begin{array}{c}0.214 \\
(0.194)\end{array}$ & $\begin{array}{c}0.287 * * \\
(0.118)\end{array}$ \\
\hline Time period & $\begin{array}{c}0.003 \\
(0.149)\end{array}$ & $\begin{array}{l}-0.142 \\
(0.182)\end{array}$ & $\begin{array}{c}-0.750 * * * \\
(0.157)\end{array}$ & $\begin{array}{c}-.379 * * * \\
(0.091)\end{array}$ \\
\hline Constant & $\begin{array}{c}42.737 * * * \\
(2.229)\end{array}$ & $\begin{array}{c}42.435^{* * *} \\
(2.225)\end{array}$ & $\begin{array}{c}18.570^{* * * *} \\
(2.179)\end{array}$ & $\begin{array}{c}20.069 * * * \\
(1.883)\end{array}$ \\
\hline $\mathrm{R}^{2}$ & 0.733 & 0.796 & 0.163 & 0.088 \\
\hline $\mathrm{N}$ & 1234 & 640 & 592 & 305 \\
\hline Wald $\chi^{2}$ & 175.81 & 203.33 & 43.75 & 23.48 \\
\hline Prob $>\chi^{2}$ & 0.000 & 0.000 & 0.000 & 0.000 \\
\hline$\#$ of replications & 1000 & 1000 & 1000 & 1000 \\
\hline
\end{tabular}

Note: Numbers reported are ordinary least squares coefficients. Bootstrapped standard errors, calculated from bootstrap samples of matching groups, are in parentheses. Errors are treated as independent across matching groups and correlated within matching groups. Time periods are numbered from -19 to 0 in columns 1 and 3 and from -9 to 0 in columns 2 and 4 . ***, **, and * denote significance at the 1-, 5-, and 10-percent level, respectively. 


\section{TABLE 4}

Probit model predicting the proposer's rejection risk

\begin{tabular}{|c|c|c|c|c|}
\hline & \multicolumn{4}{|c|}{$\begin{array}{c}\text { Dependent variable equals } 1 \text { if the proposer's offer is } \\
\text { rejected by all responders } \\
\text { Proposers are the units of observation }\end{array}$} \\
\hline & \multicolumn{2}{|c|}{$\begin{array}{c}\mathrm{PC} 2, \mathrm{UG}, \mathrm{RC} 2, \text { and } \mathrm{RC} 5 \\
\text { pooled }\end{array}$} & \multicolumn{2}{|c|}{$\mathrm{RC} 2$ and RC5 pooled } \\
\hline & $\begin{array}{c}\text { coef. } \\
\text { (rob. s.e.) }\end{array}$ & $\begin{array}{l}\text { marginal } \\
\text { effects }\end{array}$ & $\begin{array}{c}\text { coef. } \\
\text { (rob. s.e.) }\end{array}$ & $\begin{array}{c}\text { marginal } \\
\text { effects }\end{array}$ \\
\hline Offer & $\begin{array}{c}-0.053 * * * \\
(0.011)\end{array}$ & -.014 & $\begin{array}{c}-0.083 * * \\
(0.041)\end{array}$ & -0.004 \\
\hline PC2 & $\begin{array}{c}2.778 * * * \\
(0.441)\end{array}$ & 0.790 & & \\
\hline PC2*time period & $\begin{array}{c}0.073 * * * \\
(0.022)\end{array}$ & 0.020 & & \\
\hline $\mathrm{RC} 2$ & $\begin{array}{c}-1.861 * * * \\
(0.378)\end{array}$ & -.291 & & \\
\hline $\mathrm{RC} 2 *$ time period & $\begin{array}{c}-0.039 * * \\
(0.019)\end{array}$ & -.011 & & \\
\hline $\mathrm{RC} 5$ & $\begin{array}{l}-3.079 * * * \\
(0.430)\end{array}$ & -.383 & $\begin{array}{l}-1.443 * * * \\
(0.518)\end{array}$ & -0.090 \\
\hline RC5*time period & $\begin{array}{l}-0.046 \\
(0.034)\end{array}$ & -.012 & $\begin{array}{c}0.000 \\
(0.035)\end{array}$ & 0.000 \\
\hline Time period & $\begin{array}{l}-0.021 * \\
(0.011)\end{array}$ & -.005 & $\begin{array}{c}-0.072 * * * \\
(0.023)\end{array}$ & -0.004 \\
\hline Constant & $\begin{array}{l}1.103 * * \\
(0.431)\end{array}$ & & $\begin{array}{l}-0.358 \\
(0.644)\end{array}$ & \\
\hline $\mathrm{N}$ & 1700 & & 640 & \\
\hline Wald $\chi^{2}$ & 510.76 & & 38.60 & \\
\hline Prob $>\chi^{2}$ & 0.000 & & 0.000 & \\
\hline \# of replications & 974 & & 991 & \\
\hline
\end{tabular}

Note: Numbers reported are probit coefficients. Bootstrapped standard errors, calculated from bootstrap samples of matching groups, are in parentheses. Errors are treated as independent across matching groups and correlated within matching groups. The 20 time periods are numbered from 19 to 0 . Marginal effects are calculated at sample means. $* * *, * *$, and $*$ denote significance at the 1-, $5-$, and 10-percent level, respectively. 


\section{TABLE 5}

Pooled Probit model predicting the responder's rejection probability

\begin{tabular}{|c|c|c|}
\hline \multirow{2}{*}{\multicolumn{3}{|c|}{$\begin{array}{l}\text { Dependent variable equals } 1 \text { if the responder } \\
\text { rejects the offer (Responders are the units of } \\
\text { observation) } \\
\text { UG, RC2, RC5 pooled }\end{array}$}} \\
\hline & & \\
\hline & $\begin{array}{c}\text { coef. } \\
\text { (rob. s.e.) }\end{array}$ & $\begin{array}{c}\text { marginal } \\
\text { effects }\end{array}$ \\
\hline Offer & $\begin{array}{c}-0.065 * * * \\
(0.008)\end{array}$ & -0.020 \\
\hline $\mathrm{RC} 2$ & $\begin{array}{c}-1.076 * * * \\
(0.270)\end{array}$ & -0.268 \\
\hline $\mathrm{RC} 2 *$ time period & $\begin{array}{l}-0.023 \\
(0.015)\end{array}$ & -0.007 \\
\hline $\mathrm{RC} 5$ & $\begin{array}{c}-1.666^{* * *} \\
(0.136)\end{array}$ & -0.532 \\
\hline RC5*time period & $\begin{array}{c}-0.029 * * * \\
(0.012)\end{array}$ & -0.009 \\
\hline Time period & $\begin{array}{c}-0.019 * \\
(0.011)\end{array}$ & -0.006 \\
\hline Constant & $\begin{array}{c}1.574 * * * \\
(0.325) \\
\end{array}$ & \\
\hline $\mathrm{N}$ & 2700 & \\
\hline Wald $\chi^{2}$ & 202.02 & \\
\hline $\mathrm{P}$ & 0.000 & \\
\hline \# of replications & 977 & \\
\hline
\end{tabular}

Notes: Numbers reported are probit coefficients. Bootstrapped standard errors, calculated from bootstrap samples of matching groups, are in parentheses. Errors are treated as independent across matching groups and correlated within matching groups. The 20 time periods are numbered from 19 to 0 . Marginal effects are calculated at sample means. $* * *, * *$, and * denote significance at the 1-, 5-, and 10-percent level, respectively. 
TABLE 6

Pooled Probit models predicting the responder's rejection probability

\begin{tabular}{|c|c|c|c|c|}
\hline & \multicolumn{4}{|c|}{$\begin{array}{l}\text { Dependent variable: }=1 \text { if the responder rejects the offer } \\
\text { Observation unit: each responder is an observation }\end{array}$} \\
\hline & \multicolumn{2}{|c|}{ UG, RC2, and RC5 pooled } & \multicolumn{2}{|c|}{$\mathrm{RC} 2$, and $\mathrm{RC} 5$ pooled } \\
\hline & $\begin{array}{l}\text { coef. } \\
\text { (rob. S.e.) }\end{array}$ & $\begin{array}{l}\text { marginal } \\
\text { effects }\end{array}$ & $\begin{array}{l}\text { coef. } \\
\text { (rob. S.e.) }\end{array}$ & $\begin{array}{l}\text { marginal } \\
\text { effects }\end{array}$ \\
\hline Offer & $\begin{array}{c}-0.055 * * * \\
(0.008)\end{array}$ & -0.017 & $\begin{array}{c}-0.049 * * * \\
(0.007)\end{array}$ & -0.016 \\
\hline $\begin{array}{c}\text { Belief that all } \\
\text { others reject } \\
\text { (dummy variable) }\end{array}$ & $\begin{array}{l}1.089 * * * \\
(0.150)\end{array}$ & 0.374 & $\begin{array}{l}1.118 * * * \\
(0.136)\end{array}$ & 0.411 \\
\hline $\mathrm{RC} 2$ & $\begin{array}{l}-0.236 \\
(0.300)\end{array}$ & -0.072 & & \\
\hline $\mathrm{RC} 2 *$ time period & $\begin{array}{l}-0.013 \\
(0.020)\end{array}$ & -0.004 & & \\
\hline $\mathrm{RC5}$ & $\begin{array}{c}-0.272 \\
(0.324)\end{array}$ & -0.088 & $\begin{array}{c}0.033 \\
(0.216)\end{array}$ & 0.011 \\
\hline RC5*time period & $\begin{array}{l}-0.014 \\
(0.012)\end{array}$ & -0.004 & $\begin{array}{l}-0.000 \\
(0.016)\end{array}$ & -0.000 \\
\hline Time period & $\begin{array}{c}-0.021^{* *} \\
(0.010)\end{array}$ & -0.007 & $\begin{array}{l}-0.031 * \\
(0.017)\end{array}$ & -0.010 \\
\hline Constant & $\begin{array}{c}0.505 \\
(0.278)\end{array}$ & & $\begin{array}{c}0.365 \\
(0.249)\end{array}$ & \\
\hline $\mathrm{N}$ & 2700 & & 2240 & \\
\hline Wald $\chi^{2}$ & 153.35 & & 143.50 & \\
\hline $\mathrm{P}>\chi^{2^{n}}$ & 0.000 & & 0.000 & \\
\hline \# of replications & 977 & & 991 & \\
\hline
\end{tabular}

Notes: Numbers reported are probit coefficients. Bootstrapped standard errors, calculated from bootstrap samples of matching groups, are in parentheses. Errors are treated as independent across matching groups and correlated within matching groups. The 20 time periods are numbered from 19 to 0 . Marginal effects are calculated at sample means. ***,**, and * denote significance at the 1-, 5-, and 10-percent level, respectively. 
Figure 1: Predicted offer distributions in the UG according to the quantal response approach with selfish preferences

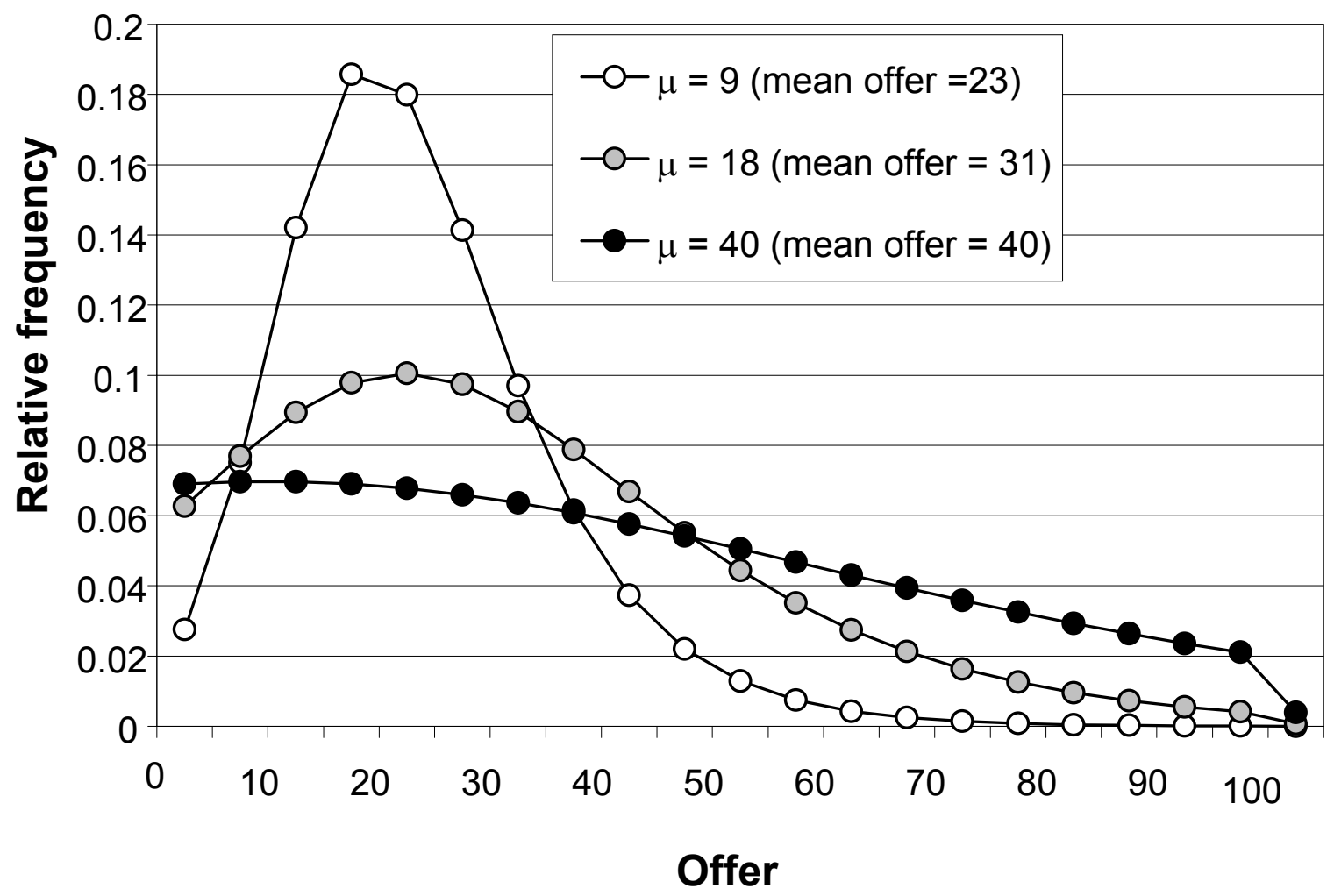

Figure 2: Prediction of responders' rejection rate according to the quantal response equilibrium approach with selfish preferences $(\mu=4)$

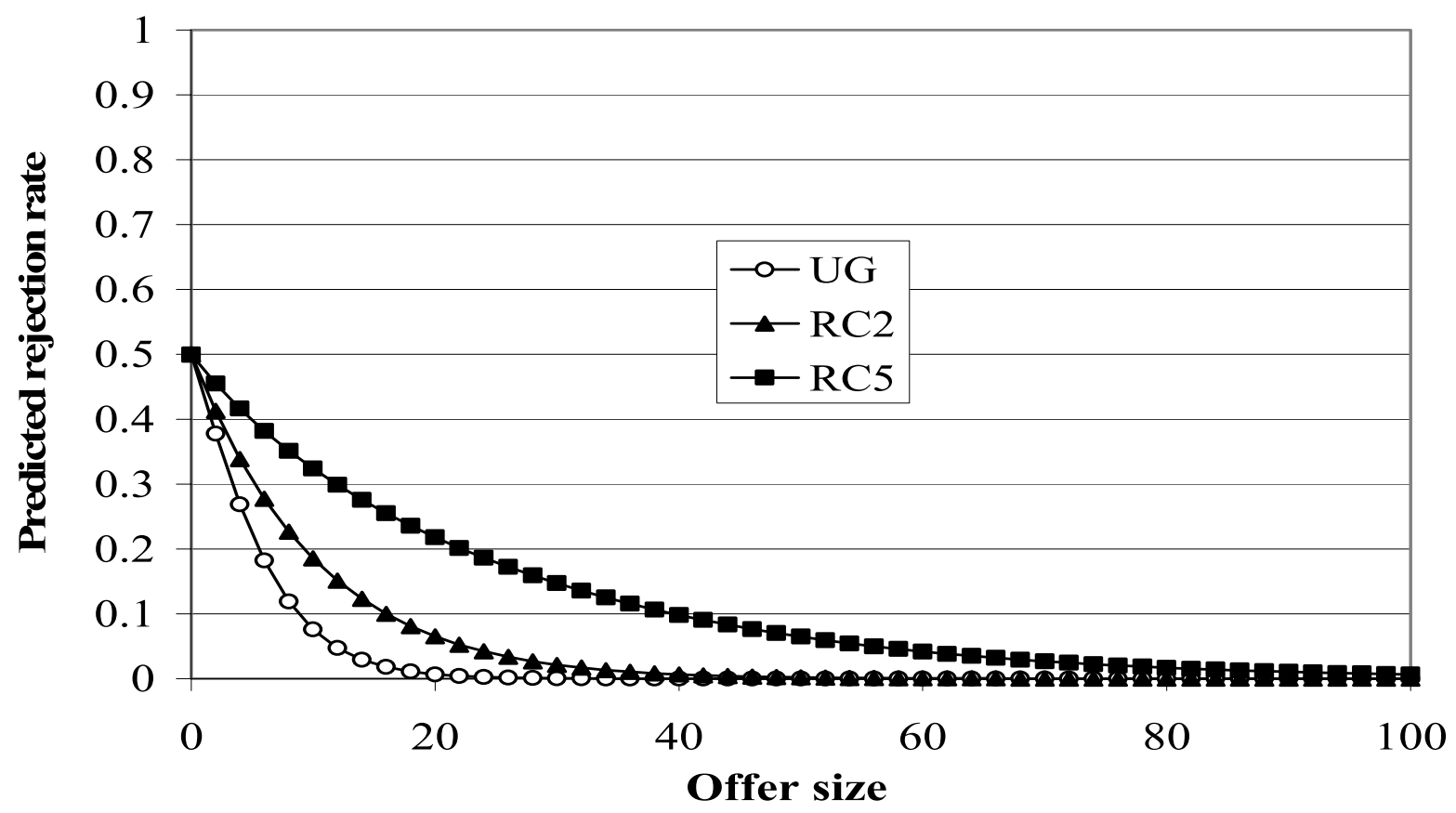


Figure 3: Average accepted offer in bargaining and market experiments

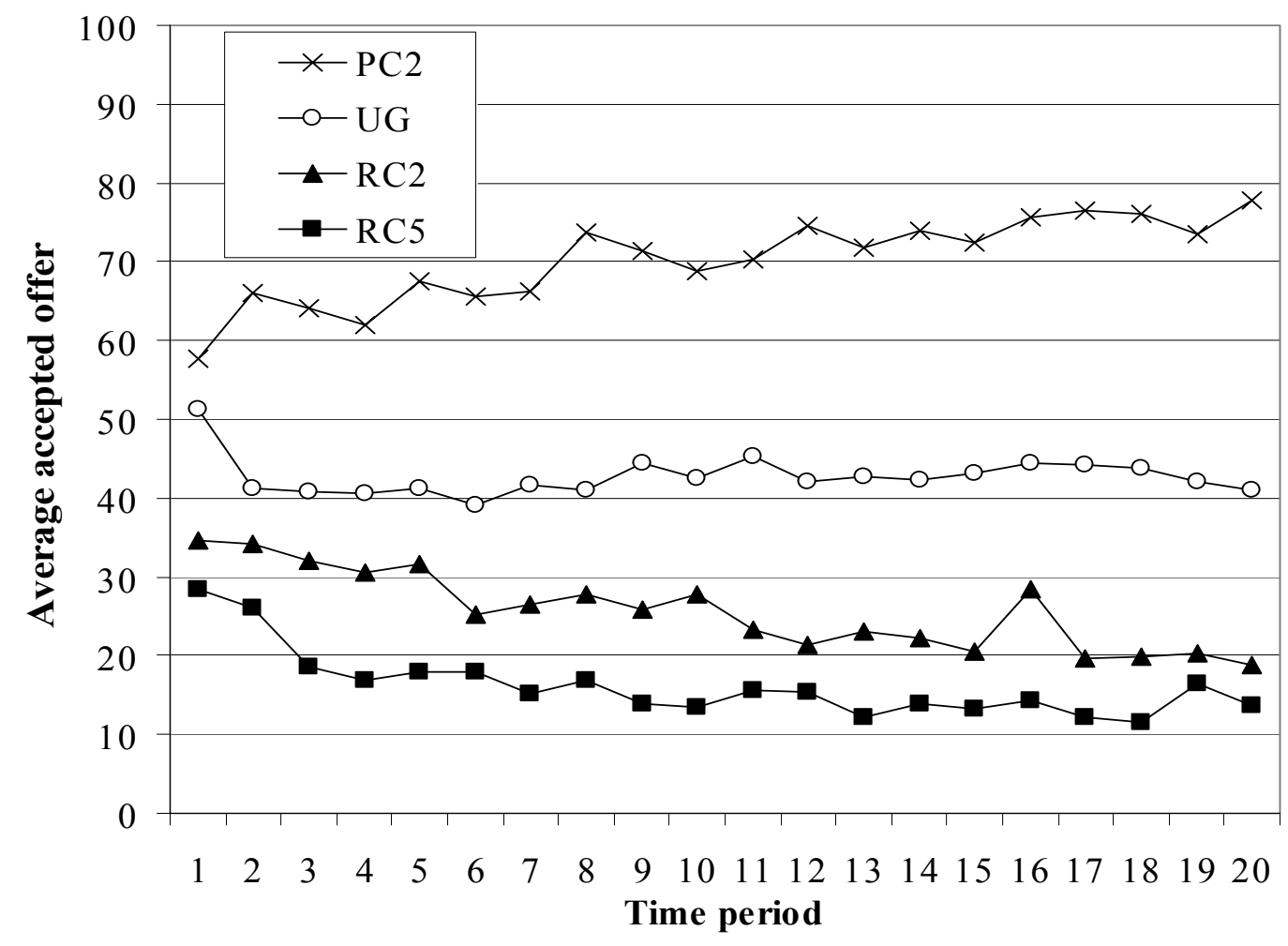


Figure 4: Proposers' rejection risk conditional on offers

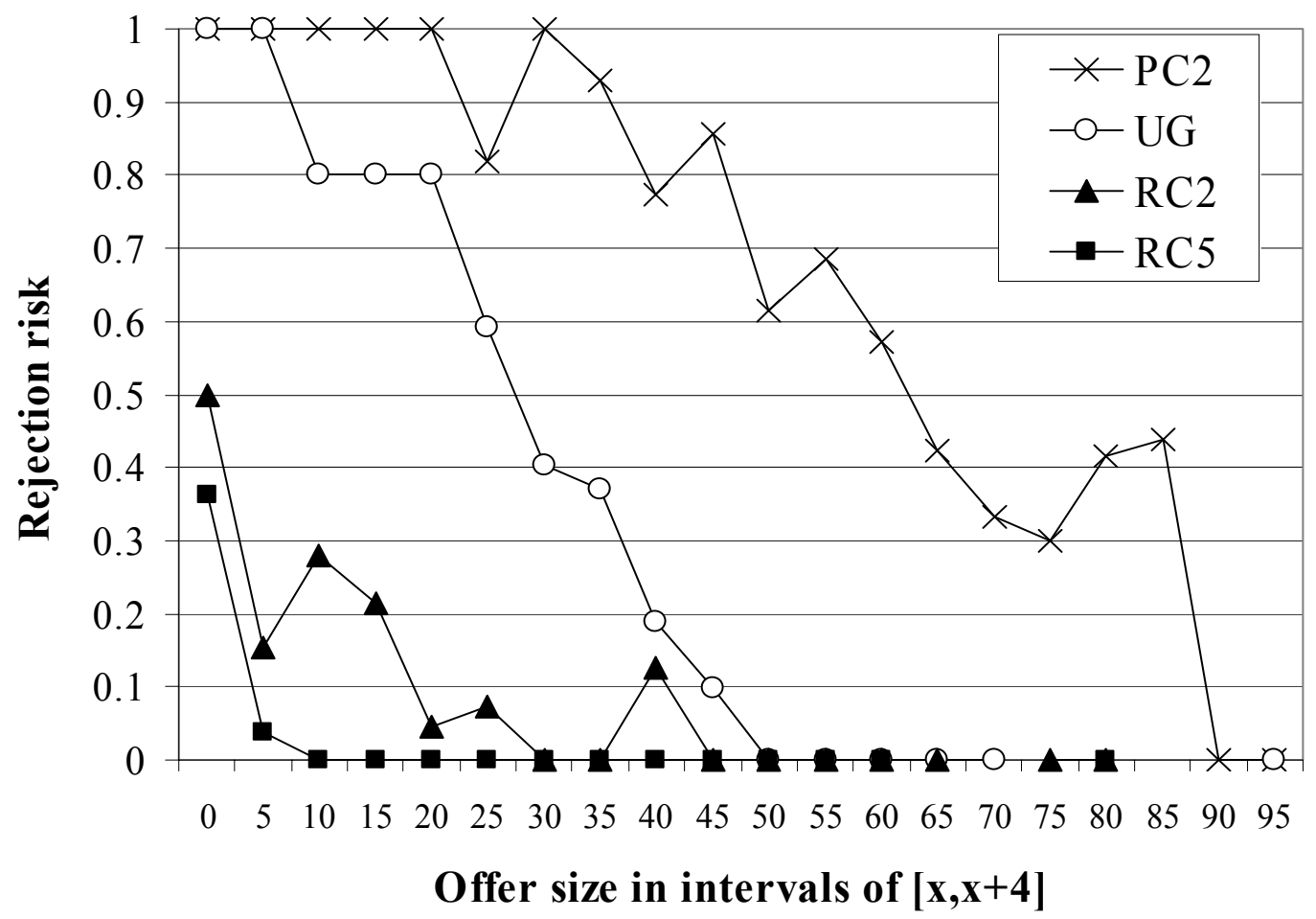

Figure 5: Proposers' expected payoff as a function of offer size

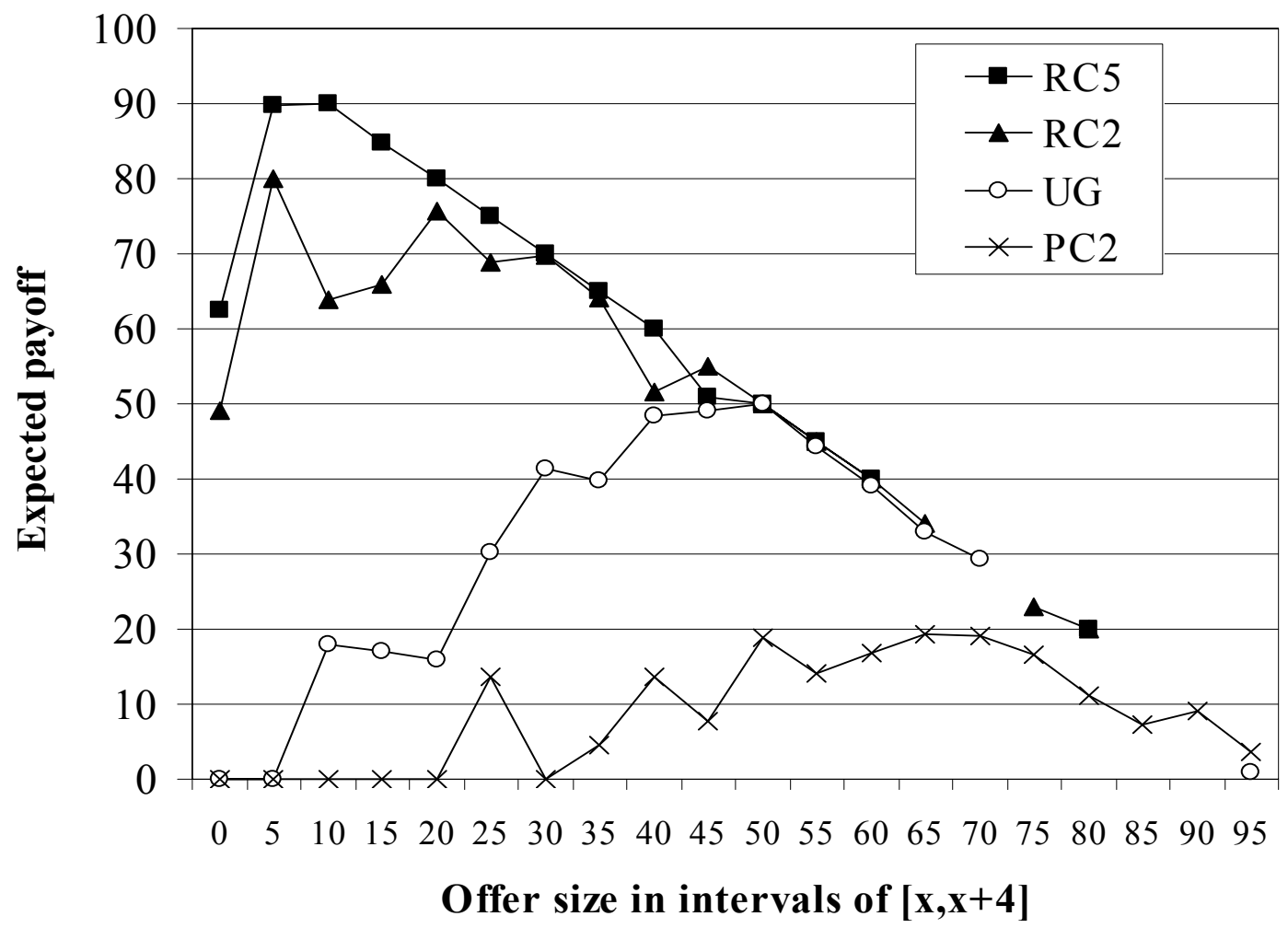


Figure 6: Responders' rejection rate conditional on offer size

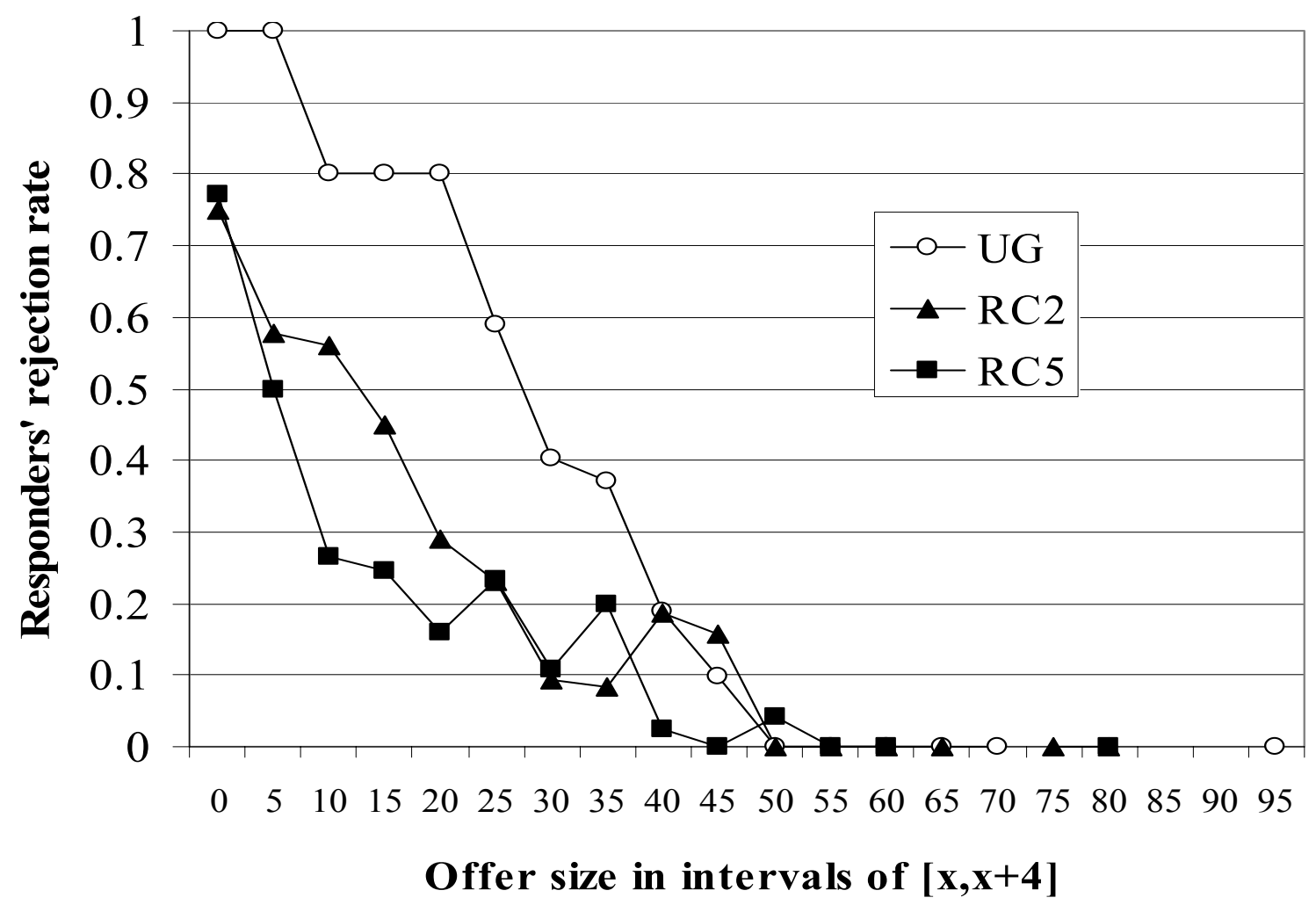

Figure 7: Responders' rejection rate in RC2 conditional on offer size and beliefs about the other responder's behavior

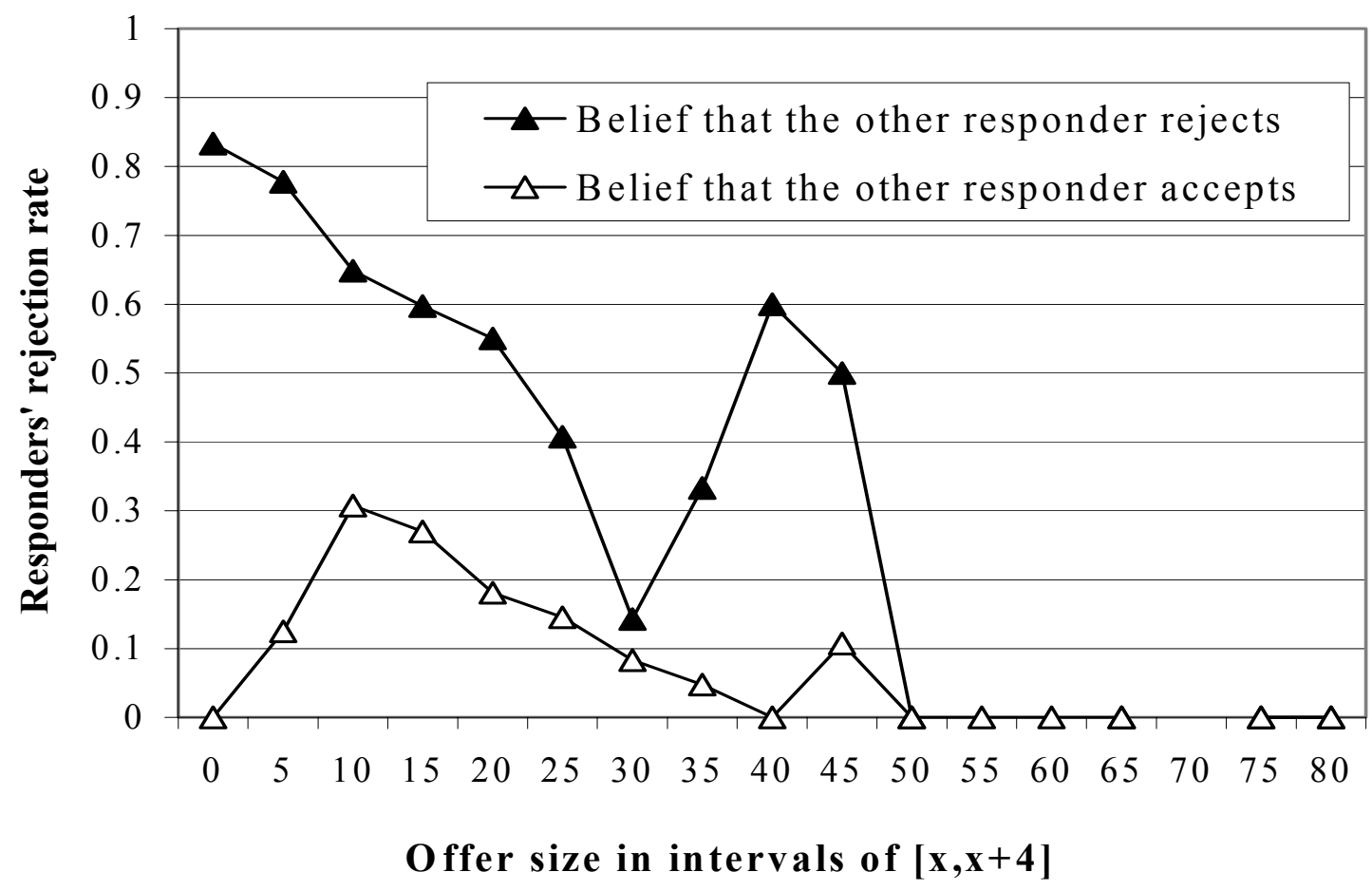


Figure 8: Cumulative frequency of actual and predicted offer distribution based on Fairness and QRE
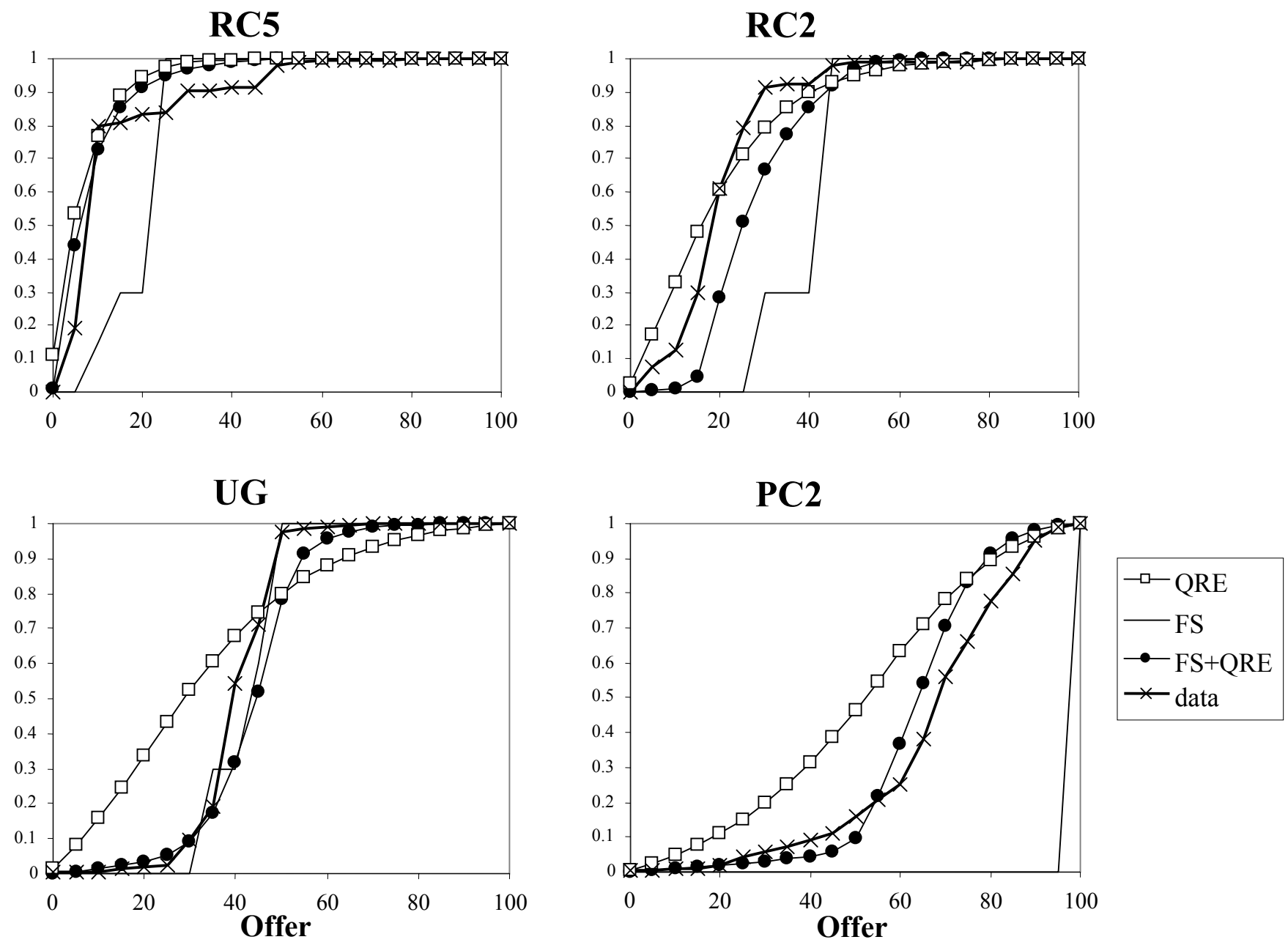